\title{
Overview of inert tracer experiments in key Belgian soil types: Relation between transport and soil morphological and hydraulic properties
}

\author{
J. Vanderborght, ${ }^{1,2}$ M. Vanclooster, ${ }^{1,3}$ A. Timmerman, ${ }^{1}$ P. Seuntjens, ${ }^{4}$ \\ D. Mallants, ${ }^{1,5}$ D.-J. Kim, ${ }^{1,6}$ D. Jacques, ${ }^{1,5}$ L. Hubrechts, ${ }^{1}$ \\ C. Gonzalez, ${ }^{1,7}$ J. Feyen, ${ }^{1}$ J. Diels, ${ }^{1,8}$ and J. Deckers ${ }^{1}$
}

\begin{abstract}
To investigate relations between solute transport, soil properties, and experimental conditions, we summarize results from leaching experiments that we carried out in a range of soils, at different scales (column (0.3-1.0 m ID, $1.0 \mathrm{~m}$ length) and field plot scale), and using different leaching rates $\left(0.5-30 \mathrm{~cm} \mathrm{~d}^{-1}\right)$. The lateral mixing regime and longitudinal dispersion were derived from time series of tracer concentrations at several depths in the soil. Field- and column-scale transport were similar in loam and silt loam soils. The mixing regime was related to soil morphological features, such as vertical tongues, stratification, macropores, and a water-repellent layer. The dispersion increased in all soils more than linearly with increasing leaching rate, implying that the dispersivity is not an intrinsic soil characteristic. The change of dispersivity with leaching rate was linked to the unsaturated hydraulic conductivity using a multidomain conceptualization of the pore space.
\end{abstract}

\section{Introduction}

In general, two parameters are used to describe the transport of inert (i.e., nonadsorbing, nondegradable, and nonvolatile) solutes through the soil: (1) the average velocity of the solute plume $v\left(L T^{-1}\right)$ and (2) the dispersion of the solute plume as it travels through the soil. The solute plume velocity $v$ is simply related to the spatially averaged water flux $J_{w}$ ( $L$ $T^{-1}$ ) and spatially averaged volumetric water content $\theta$ as $v=$ $J_{w} / \theta$. A convenient way to describe dispersion of a solute plume, which is defined by macroscopically observed concentrations, is to track displacements of a large number of microscopic dissolved particles, "solute particles." The spatial distribution of macroscopic concentrations is derived from the distribution of particle locations. The description of dispersion by continuous motions of microscopic dissolved particles was initiated by Einstein [1905] to describe molecular diffusion in aqueous solutions, used by Taylor [1921] to describe dispersion in a capillary, by Saffman [1960] to describe dispersion in a

\footnotetext{
${ }^{1}$ Laboratory of Soil and Water, Department of Land Management, Faculty of Agricultural and Applied Biological Sciences, Catholic University of Leuven, Leuven, Belgium.

${ }^{2}$ Now at Research Center Jülich, Jülich, Germany.

${ }^{3}$ Now at Department of Environmental Sciences and Land Management, Faculty of Agricultural Sciences, Catholic University of Louvain, Louvain-La-Neuve, Belgium.

${ }^{4}$ Flemish Institute for Technological Research, Mol, Belgium.

${ }^{5}$ Now at Research Center for Nuclear Energy, Mol, Belgium.

${ }^{6}$ Now at Department of Environmental Geosphere Science, Faculty of Science and Engineering, Korea University, Seoul, Republic of Korea.

${ }^{7}$ Now at Faculty of Engineering, Universidad Nacional de Colombia, Bogotá, Colombia.

${ }^{8}$ Now at International Institute for Tropical Agriculture, Ibadan, Nigeria.
}

Copyright 2001 by the American Geophysical Union.

Paper number 2000WR000110.

0043-1397/01/2000WR000110\$09.00 pore network, and by Dagan [1982] to describe dispersion in a heterogeneous aquifer.

Therefore the key to understanding the dispersion of inert solutes in a soil is the velocity distribution of the microscopic particles in combination with the velocity changes along the particle trajectories. A "mixing" time $t^{*}(T)$ that corresponds to the time interval when a particle travels with a constant velocity or "remembers" its velocity defines the particle's velocity changes along its trajectory. Since the process that moves particles into regions with other velocities and makes particles change their velocity is often related to a lateral, i.e., transverse to the mean flow, displacement, it is called the "lateral mixing" process [Koch and Flühler, 1994; Flühler et al., 1996]. A comparison between the particle travel time and the mixing time forms the basis for discrimination between different "transport processes" or "mixing regimes" [Simmons, 1982; Jury and Flü$h l e r, 1992]$. If the "mixing" time $t^{*}$ is much smaller than the solute travel time, the dispersion of a solute plume can be described as a Fickian, concentration-gradient-driven process [Dagan, 1989], and the transport process is called a convectivedispersive process. For this transport process or mixing regime the classical convection dispersion equation (CDE), assuming macroscopically uniform flow, can be used to predict the plume dispersion. However, the CDE failed to describe the observed dispersion in several transport experiments in soils [e.g., Corey et al., 1963; Butters and Jury, 1989; Khan and Jury, 1990]. In some soils the mixing time was longer than the average travel time, and solutes were incompletely mixed laterally between regions with high and low velocities. The opposite of a convective-dispersive process is the so-called stochastic-convective process [Simmons, 1982], which describes the dispersion of the plume when the travel time of the particles is much smaller than $t^{*}$. Stream tube models [e.g., Simmons, 1982; Jury, 1982] that assume a constant particle velocity along its trajectory and no lateral solute mixing were used to predict solute transport for a stochastic-convective transport process. 
Both convective-dispersive and stochastic-convective processes are so-called asymptotic transport processes and apply for solute travel times which are much larger and much smaller, respectively, than the mixing time $t^{*}$. To bridge the gap between these asymptotic processes, transport models that conceptualize lateral solute mixing must be used. These models can be subdivided into two classes. In the first class, lateral solute mixing and the mixing time are derived from the spatial distribution of macroscopic hydraulic properties using stochastic-continuum flow and transport equations [e.g., Russo, 1995a, 1995b]. In the second class of models, multidomain models, the porous medium is subdivided in two [e.g., Coats and Smith, 1964; van Genuchten and Wierenga, 1976; Jarvis et al., 1991; Chen and Wagenet, 1992; Gerke and van Genuchten, 1993] or more [Steenhuis et al., 1990; Skopp and Gardner, 1992; Gwo et al., 1995; Durner and Flühler, 1996] subdomains in which solutes advectively move at different velocities and between which solutes are exchanged by diffusion and/or advection.

The variability of the advection velocities and the ratio of the mixing time to the travel time, or the "mixing regime," are 'determined by the spatial structure of the flow field in the porous medium, which is, in turn, related to the structure of the porous medium. Therefore soil characteristics that are related to the structure of the porous medium are most likely closely related to dispersion process and transport parameters. At the microscopic scale, local variations in advection velocity result from the irregular nature of the pore network. Klotz et al. [1980] observed larger dispersion in aquifer sediments with a larger grain size (longer pore length and "mixing" time $t^{*}$ ) and a wider grain size distribution (larger variability in pore sizes and microscopic advection velocities). A correlation between the width of the pore size distribution, which was derived from the retention curve, and the dispersion in soil cores was reported by Vervoort et al. [1999]. At a larger scale the size and geometry of soil peds or aggregates influence the lateral mixing regime and dispersion process. Vervoort et al. [1999] present a conceptual relation between soil structural development stage and the degree of preferential flow, which is the opposite of lateral mixing. At the macroscopic scale the structure of the flow field depends on the variability and the spatial correlation of the hydraulic conductivity [Russo, 1995a, 1995b]. Kasteel [1997] and Vanderborght et al. [1997b] predicted solute dispersion observed in a field-scale leaching experiment from the spatial variability of measured soil hydraulic properties. Vanderborght et al. [1997b] concluded that the mixing regime could be fairly well reproduced for smaller flow rates if small correlation scales of the hydraulic properties were assumed. For higher flow rates the dispersion was largely underestimated owing to a large variability of particle velocities at the pore scale when macropores were activated.

In unsaturated media the structure of the water-filled pore space and, hence, the flow field depends on the saturation degree [Flury et al., 1994]. Especially when macropores, which deviate by virtue of their size and continuity from the micropores between normally packed solid particles in the soil matrix, are activated, the variance of local advection velocities and the ratio of the mixing time to the travel time increase dramatically with increasing flow rate [e.g., White, 1985; Dyson and White, 1989; Bouma, 1991]. On the other hand, a decrease in water saturation may result in larger tortuosity of the solute trajectories, a disconnection of continuous flow paths, and a physical nonequilibrium due to a slow diffusive exchange of solutes between mobile and immobile pore regions. Conse- quently, in some experimental studies [e.g., Corey et al., 1963; De Smedt et al., 1986; Maraqa et al., 1997] a higher solute dispersion was found for unsaturated than for saturated flow conditions. Analysis of flow and transport in unsaturated soils with spatially varying macroscopic soil properties using stochastic-continuum equations has revealed that the macroscopic pore water velocity distribution and the ratio of the mixing time to the travel time depend largely on the saturation degree and, hence, flow rate [e.g., Russo, 1995a, 1995b; Roth and Hammel, 1996]. Under dry conditions the plume dispersion was found to decrease with increasing flow rate.

Since the mixing time $t^{*}$ and the variance of the advection velocities and, hence, the solute dispersion in natural soils are very difficult to derive directly from measurable soil properties, there is still a large demand for experiments that characterize solute transport in soils [Flühler et al., 1996]. Especially information on which transport model and which model parameters can be best used for a specific soil type and how they might depend on the saturation degree of the soil and the boundary conditions is still missing.

The objectives of this paper are threefold. First we investigate the link between soil structure and mixing regime. Since important information about the structure of a soil profile is embedded in diagnostic features that are used in soil classification systems, we look for a relation between the lateral mixing regime and these diagnostic features. Second we investigate the effect of the experimental condition, the scale of experiment and the applied boundary conditions that define the saturation degree in the soil, on the observed solute transport. Finally, we investigate whether information about the pore network that is contained in the hydraulic conductivity curve can be linked to the observed solute dispersion process in different soils and for different boundary conditions using a multidomain conceptualization of the pore space. To achieve these objectives, we summarize the results of leaching experiments that were carried out in a range of soils at different scales and for different leaching rates [Jacques et al., 1998; Seuntjens et al., 1999; Vanderborght et al., 1997a, 2000a].

\section{Theory}

\subsection{Definition of Longitudinal Dispersion Coefficient} $D_{L}$, Longitudinal Dispersivity $\lambda_{L}$, and Identification of "Mixing Regime"

For a convective-dispersive mixing regime (travel time much greater than mixing time $t^{*}$ ) the dispersion of the plume is described by the convection dispersion equation (CDE), and the longitudinal dispersion coefficient $D_{L}\left(L^{2} T^{-1}\right)$ defines the dispersion of the plume in the direction of the flow. This dispersion coefficient is related to the variance of the local advection velocities, $\sigma_{u}^{2}\left(L^{2} T^{-2}\right)$, and the mixing time $t^{*}$ as [e.g., Dagan, 1989; Jury and Roth, 1990]

$$
D_{L}=\sigma_{u}^{2} t^{*}+D_{0}
$$

with $D_{0}\left(L^{2} T^{-1}\right)$ the effective molecular diffusion coefficient. The dispersion coefficient $D_{L}$ defines the spread of solute travel distances, $\operatorname{Var}(z ; t)\left(L^{2}\right)$, around the average travel distance, $E(z ; t)(L)$, in the direction of the mean flow at a certain time $t$. Alternatively, $D_{L}$ defines the spread of solute arrival time, $\operatorname{Var}(t ; z)\left(T^{2}\right)$, around the average solute arrival time $E(t ; z)(T)$ at a certain depth $z$ [Jury and Sposito, 1985]:

$$
D_{L}=\frac{\operatorname{Var}(z ; t)}{2 t} ; \quad D_{L}=\frac{\operatorname{Var}(t ; z) z^{2}}{2[E(t ; z)]^{3}} .
$$


The travel distance and travel time statistics are derived from concentration depth profiles and time series, respectively, of solute fluxes for a spatial concentration and a temporal solute flux spike at $t=0$ and $z=0$, respectively [e.g., Jury and Roth, 1990]:

$$
\begin{aligned}
& \operatorname{Var}(z ; t)=\frac{\int \theta C(z ; t)[z-E(z ; t)]^{2} d z}{M_{0}}, \\
& E(z ; t)=\frac{\int \theta C(z ; t) z d z}{M_{0}} \\
& \text { for } \int \theta C(z ; t) d z=\left.M_{0} \delta(z)\right|_{t=0} \\
& \operatorname{Var}(t ; z)=\frac{\int J s(t ; z)[t-E(t ; z)]^{2} d t}{M_{0}}, \\
& E(t ; z)=\frac{\int J_{S}(t ; z) t d t}{M_{0}}, \text { for } J S(t ; z)=\left.M_{0} \delta(t)\right|_{z=0},
\end{aligned}
$$

where $C(z ; t)\left(M L^{-3}\right)$ is the averaged concentration across a horizontal surface at depth $z$ and time $t, \theta\left(L^{3} L^{-3}\right)$ is the volumetric water content, $J_{S}(t ; z)\left(M L^{-2} T^{-1}\right)$ is the solute flux across a compliance plane which is perpendicular to the mean flow direction, $M_{0}\left(M L^{-2}\right)$ is the amount of solute mass added per unit area, and $\delta(z)\left(L^{-1}\right)$ and $\delta(t)\left(T^{-1}\right)$ are Dirac functions. If the plume dispersion in a vertically homogeneous soil profile can be predicted by the classical CDE, $D_{L}$ and $v=z / E(t ; z)$ are constants, so that from (2) follows $\operatorname{Var}(z ; t) \sim t$ and $\operatorname{Var}(t ; z) \sim z$.

Even if the CDE cannot predict dispersion, (2) can still be used to define "apparent" dispersion coefficients, either at a certain travel time from the spatial moments of the plume or at a certain travel distance from the temporal moments of breakthrough curve (BTC). For a stochastic-convective mixing regime (travel time much less than mixing time $t^{*}$ ) the variance of the microscopic particle locations, $\operatorname{Var}(z ; t)$, and the variance of particle arrival times at a compliance surface, $\operatorname{Var}(t ; z)$, increase quadratically with travel time and travel distance, respectively [Simmons, 1982; Jury and Roth, 1990]. Hence, for a stochastic-convective transport regime, the apparent dispersion coefficient that is derived using (2) is a linear function of travel time and mean solute displacement. As a consequence, the change of the apparent $D_{L}$ with travel time or travel distance can be used to identify the "mixing regime" in the soil.

\subsection{Horizontal-Scale Effect on $\boldsymbol{D}_{L}$}

Besides scaling of $D_{L}$ with depth due to a lack of lateral solute mixing, $D_{L}$ may also scale with the horizontal scale across which concentrations are averaged. The variability of arrival times or travel distances that are observed in a breakthrough curve (BTC) or depth profile of concentrations reflects the variability of advection velocities within this horizontal averaging scale only. Therefore, when advection velocity variations are present at a larger scale, the observed variance of travel times and travel distances increases with increasing horizontal averaging scale. The horizontal-scale effect is investigated by averaging BTCs that are measured at several locations along a horizontal transect using the procedure discussed by van Wesenbeeck and Kachanoski [1991]. For a certain horizontal averaging scale $x$, observation points along the transect that are at most a distance $x$ separated were grouped. Within each group an average BTC was calculated from the BTCs at the different locations in the group, and the dispersion coefficient was derived from the averaged BTC. The dispersion coefficient for a horizontal averaging scale $x$ is the average dispersion coefficient of the different groups.

\subsection{Definition of Longitudinal Dispersivity $\lambda_{L}$ and Effective Flow Rate $J_{\text {weff }}$ and Identification of the Effect of the Flow Rate or Saturation Degree on the Dispersion Process}

If the geometry of the water-filled pore space does not change with the flow rate and if the local flow rate is proportional to the macroscopic head gradient, the coefficient of variation of the solute velocities $\mathrm{CV}_{u}=\sigma_{u} / v$ is independent of the average flow rate and, hence, a material constant. If molecular diffusion drives lateral solute mixing, e.g., lateral mixing within a pore [Taylor, 1953] and diffusion into dead-end pores [Coats and Smith, 1964], the mixing time does not depend on the flow velocity, so that $D_{L} \sim v^{2}$ [Passioura, 1971]. If lateral mixing is driven by advection rather than diffusion, the solute mixing time is inversely proportional to the average flow rate, $t^{*}=l^{*} / v$ with $l^{*}$ a characteristic pore length [Skopp and Gardner, 1992]. As a consequence,

$$
\sigma_{u}^{2} t^{*}=\mathrm{CV}_{u}^{2} l^{*} v=\lambda_{L} v
$$

where $\lambda_{L}(L)$ is the dispersivity, which is a material constant. From (1) and (4) it follows [Bear, 1972]

$$
D_{L}=\lambda_{L} v+D_{0}
$$

However, in unsaturated soils, an increase in flow rate results in the activation of larger pores, and neither $\mathrm{CV}_{u}$ nor $l^{*}$ can be assumed to be invariant with $v$. The effect of the flow rate and degree of saturation on the spatial structure and variability of the flow field in unsaturated soils can be inferred from changes of $\lambda_{L}$ with flow rate and saturation degree.

For transient flow leaching experiments it is important to define the mean flow rate during a transient flow experiment so that the observed dispersivity can be linked to a flow rate parameter. For a periodic transient flow regime (quasi steady state) with only downward water fluxes a time-averaged flow rate $\left\langle J_{w}\right\rangle$ and an effective flow rate $J_{w e f f}$ are defined in terms of the time, $\Delta t$, between the start of subsequent water applications and the water depth $I(L)$ that is applied during each application [Vanderborght et al., 2000b]:

$$
\left\langle J_{w}\right\rangle=I / \Delta t,
$$

$$
J_{w \mathrm{eff}}(z)=\frac{1}{z \Delta t\left\langle J_{w}\right\rangle} \int_{0}^{z} \int_{0}^{\Delta t} J_{w}^{2}\left(z^{\prime}, t^{\prime}\right) d t^{\prime} d z^{\prime},
$$

where $J_{w}(z, t)$ is the water flux at depth $z$ and time $t$. The effective flow rate $J_{w e f f}$ is the average flow rate of a set of water packages with equal volume that cross a certain depth in the soil profile. In a similar vein the time-averaged water flux $\left\langle J_{w}\right\rangle$ is the average flow rate of a set of (possibly empty) water packages that are collected over a constant time interval at a 


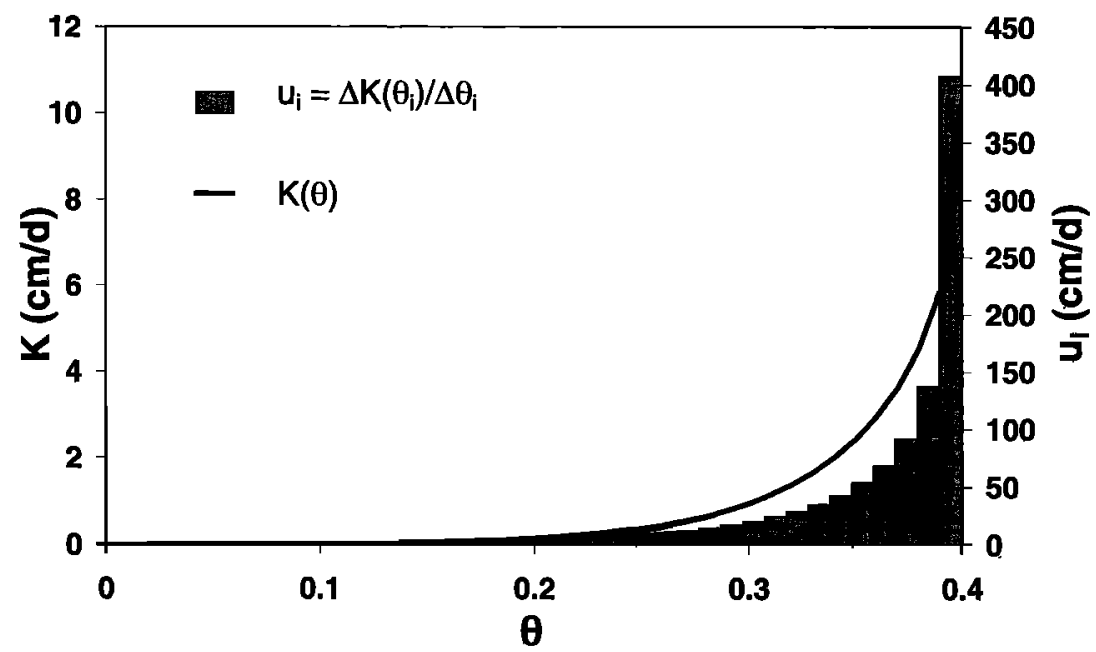

Figure 1. Distribution of pore water velocities $u$ in different pore classes $\Delta \theta$ derived from the relation between the hydraulic conductivity $K$ and the water content $\theta$.

certain depth in the soil profile. Therefore $\left\langle J_{w}\right\rangle$ can be interpreted as a measure for the flow rate at which water is flowing most of the time whereas the effective water flux $J_{w \text { eff }}(z)$ represents the flow rate at which most of the water passes a certain depth in the soil profile. Because of the highly nonlinear flow process in unsaturated soil, temporal fluctuations of water fluxes at the soil surface are buffered so that $J_{\text {weff }}(z)$ converges to $\left\langle J_{w}\right\rangle$ deeper in the unsaturated soil profile. The depth at which $J_{w e f f}(z)$ virtually converges to $\left\langle J_{w}\right\rangle$ depends on the hydraulic soil properties and the frequency and dose of the water application. For frequent applications of small water doses, $J_{w \text { eff }}(z)$ may be approximated by $\left\langle J_{w}\right\rangle$ in virtually the entire soil profile.

Vanderborght et al. [2000b] derived this definition of $J_{\text {weff }}(z)$. They found that for a dispersivity that depends on the flow rate the spreading of a breakthrough curve observed during a transient flow leaching experiment can be approximated assuming a steady state flow leaching when the time coordinate is transformed to a solute penetration depth coordinate and the dispersivity is estimated from $J_{\text {weff }}(z)$. The solute penetration depth coordinate $\zeta(t)$, or the depth of the solute front at time $t$, is defined as

$$
\int_{0}^{t} J_{w}\left(z=0 ; t^{\prime}\right) d t^{\prime}=\int_{0}^{\zeta(t)} \theta\left(z^{\prime} ; t\right) d z^{\prime}
$$

Assuming that the water content and water flux remain constant with depth over the narrow region of the displacement front, the general form of the CDE reduces to a simpler steady state form by transforming the time coordinate to the solute penetration depth coordinate [De Smedt and Wierenga, 1978; Vanderborght et al., 2000b].

\subsection{Multidomain Conceptualization of the Pore Space}

A concept which allows the derivation of solute velocity variability at the pore scale from the relation between the hydraulic conductivity $K\left(L T^{-1}\right)$ and the water content $\theta$ is the multidomain conceptualization of the pore space. This concept was introduced by Steenhuis et al. [1990]. In this model the pore space is subdivided into different subclasses $\Delta \theta_{\imath}$, and the pore water velocity $u_{i}\left(L T^{-1}\right)$ in each subclass is estimated assuming a unit hydraulic gradient as

$$
u_{\imath}=\frac{\Delta K\left(\theta_{\imath}\right)}{\Delta \theta_{\imath}}
$$

where $\Delta K\left(\theta_{1}\right)=K\left(\theta_{i-1}+\Delta \theta_{\imath}\right)-K\left(\theta_{1-1}\right)$ is the increase in hydraulic conductivity when the pore class $\Delta \theta_{\imath}$ is filled with water. Replacing (9) by its differential form, the distribution of pore water velocities $\operatorname{PDF}\left(u ; \theta, J_{w}\right)$ and the variance of pore water velocities $\sigma_{u}^{2}\left(\theta, J_{w}\right)$ are defined for each degree of saturation or water flux [Dumer and Flühler, 1996]:

$$
\sigma_{u}^{2}\left(\theta ; J_{w}\right)=\frac{1}{\theta\left(J_{w}\right)} \int_{\theta=0}^{\theta\left(J_{w}\right)}\left(\frac{d K\left(\theta^{\prime}\right)}{d \theta^{\prime}}\right)^{2} d \theta^{\prime}-\left(\frac{K\left[\theta\left(J_{w}\right)\right]}{\theta\left(J_{w}\right)}\right)^{2} .
$$

Figure 1 illustrates the velocity distribution in different pore classes $\Delta \theta_{i}$, which is derived from the $K(\theta)$ relation. Note the different scales of the hydraulic conductivity and the velocities.

Because of the steep $K(\theta)$ when the soil is close to saturation, the velocities in the last filled pore classes are very large. As explained in section 2.1 , to predict the solute dispersion, information about the mixing time $t^{*}$ is also required. Skopp and Gardner [1992] assumed that the exchange rate of solutes between different pore regions is linearly related to the advection rate in the pore regions, so that $t^{*}=l^{*} / v$ with $l^{*}$ a characteristic pore length. Assuming that $D_{0}$ can be neglected and $t^{*}=l^{*} / v$, it follows from (4), (5), and (11) that

$$
\begin{aligned}
\frac{D_{L}}{v} & \approx \lambda_{L}=l^{*} \mathrm{CV}_{u}^{2} \\
& =l^{*}\left(\frac{\theta\left(J_{w}\right)}{K\left[\theta\left(J_{w}\right)\right]^{2}} \int_{\theta=0}^{\theta\left(J_{w}\right)}\left(\frac{d K\left(\theta^{\prime}\right)}{d \theta^{\prime}}\right)^{2} d \theta^{\prime}-1\right),
\end{aligned}
$$

where $\mathrm{CV}_{u}^{2}=\sigma_{u}^{2}\left(\theta, J_{w}\right) / v^{2}$ and $v=K\left[\theta\left(J_{w}\right)\right] / \theta\left(J_{w}\right)$.

\section{Soil Properties and Experimental Setup}

Leaching experiments were carried out in seven different soils: a sandy soil with a deep humus-rich plaggen horizon and 
a shallow water table (Gleyi-Plaggic Anthrosol (Arenic), Food and Agriculture Organization [1998]), a sandy soil with an eluvial horizon overlying a horizon with iron and organic carbon accumulation (Haplic Podzol), a sandy soil with an eluvial horizon overlying a highly degraded illuvial clay horizon (Lamellic Arenosol), a sandy loam soil with a highly degraded illuvial clay horizon (Lamelli-Luvic Arenosol (Eutric)), a loam soil consisting of a layer of colluvial material overlying a buried illuvial clay horizon (Eutric Regosol), a silt loam soil with a plough layer overlying an illuvial clay horizon (Eutric Luvisol), and a silt loam soil with an illuvial clay horizon in which vertical tongues of clay and iron-depleted material are present (SiltiStagnic Albeluvisol). Photographs of the different soil profiles are shown in Plate 1. For the Lamelli-Luvic Arenosol a picture of a similar profile taken at another location is shown. The textural composition, organic carbon content, and bulk density of the different soil horizons are listed in Table 1. The shallow water table in the Anthrosol bleached the sand under the plaggen horizon nearly completely. In the illuvial clay horizons of the Lamellic Arenosols the clay accumulations form clearly visible horizontal bands.

The parameters of the $\theta(h)$ and $K(h)(h(L)$ is the suction head) model functions of the different soils are listed in Table 2. Except for the Podzol and the Albeluvisol, two methods were combined to determine $K(h)$ : the crust method [Bouma et al., 1983] for low suctions (up to $50 \mathrm{~cm}$ suction) and the hot-air method [Arya et al., 1975] for high suctions. For the Albeluvisol, $K(h)$ was determined on $5 \mathrm{~cm}$ diameter and 5.1 $\mathrm{cm}$ high samples using the multistep outflow method [van Dam et al., 1994]. For the Podzol, saturated hydraulic conductivities were derived from infiltration experiments. Since different functions were used to describe $\theta(h)$ and $K(h)$, the hydraulic properties of the different soils cannot be compared directly from the parameters given in Table 2. In Figure 2 we plotted the conductivity $K$ versus the relative degree of saturation $\Theta=$ $\left[\theta(h)-\theta_{r}\right] /\left(\theta_{s}-\theta_{r}\right)\left(\theta_{s}\right.$ is the saturated and $\theta_{r}$ is the residual volumetric water content) for the different soil horizons. The $K(\Theta)$ relation is used to estimate the solute dispersion for a specific leaching rate based on the multidomain conceptualization of the pore space (equation (11)).

We performed leaching experiments with $\mathrm{CaCl}_{2}$ as a tracer to characterize the transport properties of the different soils. The tracer experiments were carried out in $1 \mathrm{~m}$ long undisturbed soil monoliths (two replicates for each soil) with a diameter of $0.3 \mathrm{~m}$ (small lysimeters) or $0.8 \mathrm{~m}$ (large lysimeters) and in 4.5 by $12 \mathrm{~m}$ field plots where concentrations were measured along a $8 \mathrm{~m}$ long by $0.9 \mathrm{~m}$ deep transect. We monitored the displacement of the initial soil solution by the $\mathrm{CaCl}_{2}$ solution at several depths in the soil profile using horizontally installed time domain reflectometry (TDR) probes that measured the bulk soil electrical conductivity. In some of the lysimeter experiments, concentrations were also measured in the drainage water. To avoid water and solute redistribution in the soil profile by upward water fluxes and plant uptake, soil surfaces were covered to minimize evaporation losses, and all experiments were performed in bare soils. In some experiments a steady state leaching rate was applied using a peristaltic pump or drip emitters. In the field experiments a virtually steady flow rate was obtained using a sprinkler irrigation system that frequently $(0.3-0.5 \mathrm{~min}$ application time every $20-48$ min) applied small water doses $(0.4-0.5 \mathrm{~mm})$. For these experiments, $J_{w e f f}(z)$ was approximated by $\left\langle J_{w}\right\rangle$. In the other experiments we periodically applied over a short time period the same amount of water to establish a quasi steady state flow regime. To calculate the effective flow rate $J_{w \text { eff }}(z)$ at a certain depth in the soil profile (equation (7)), the water flux $J_{w}(z, t)$ was calculated using a mass balance from the infiltration flux at the soil surface (which was equal to zero when no water was applied) and water content measurements at different depths in the soil profile or from simulated water fluxes using the Richards equation for the imposed flux boundary at the soil surface. Table 3 summarizes information on the setup of the leaching experiments. More detailed information on the experiments is given by Jacques et al. [1998], Seuntjens et al. [1999], and Vanderborght et al. [1997a, 2000a].

To determine the solute dispersion and the mixing regime, an apparent dispersivity $\lambda_{L}$ was derived at each observation depth by fitting the solution of the steady state flow convection dispersion equation (CDE) to the observed time series of concentrations or breakthrough curve (BTC). The solution of the $\mathrm{CDE}$ for a third and first type boundary condition at the soil surface was used for the in situ TDR measured resident concentration and the flux concentrations measured in the effluent, respectively [Parker and van Genuchten, 1984]. It should be noted that estimating $\lambda_{L}$ from fitting the solution of the CDE to a BTC of in situ measured resident concentrations implies the a priori assumption of a convective-dispersive transport process. Viewing a stochastic-convective process falsely as a convective-dispersive one leads to a small overestimation of $\lambda_{L}$ when the solution of the CDE is fitted to a resident concentration BTC [Jacques et al., 1998]. Therefore, in case transport was described as a stochastic-convective process, we used the procedure proposed by Jacques et al. [1998] to derive $D_{L}$ from BTCs of resident concentrations.

The maximum solute travel distance that is considered in our experiments $(1 \mathrm{~m}$ for the lysimeter experiments and $0.9 \mathrm{~m}$ for the field plot experiments) is relatively small compared with the travel distances that were suggested by Jury and Sposito [1985] to investigate solute dispersion and mixing regime. Variability in local concentrations measurements obtained from suction samplers that sample only a small volume of soil, uncertainty in the observed concentration mode (resident or flux) by suction samplers, and the nonsteady water flow close to the soil surface may lead to large uncertainty on measured concentrations, so that a large travel distance is required to discriminate between different mixing regimes. With TDR the uncertainty on the concentration measurements is reduced since the measurement volume of the TDR probes is considerably larger and volume-averaged or resident concentrations are measured. TDR measurements can be made with a high temporal resolution, and the effect of transient water flow on solute transport can be monitored. These factors reduce the uncertainty on measured concentrations so that the mixing regime can be determined for the travel distances considered in this study.

\section{Results and Discussion}

\subsection{Horizontal-Scale Effect}

For the two field-scale experiments, one in the Regosol and one in the Albeluvisol, the effect of the horizontal observation scale on the estimated solute dispersion was evaluated from concentration measurements at 24 locations (separation distance $0.33 \mathrm{~m}$ ) along a $8 \mathrm{~m}$ long horizontal transect [Jacques et al., 1997]. In Figure 3, $\lambda_{L}$ is plotted versus the horizontal averaging scale $x$. For both soils, $\lambda_{L}$ increases little with in- 
Gleyi-Plaggic Anthrosol (Arenic)

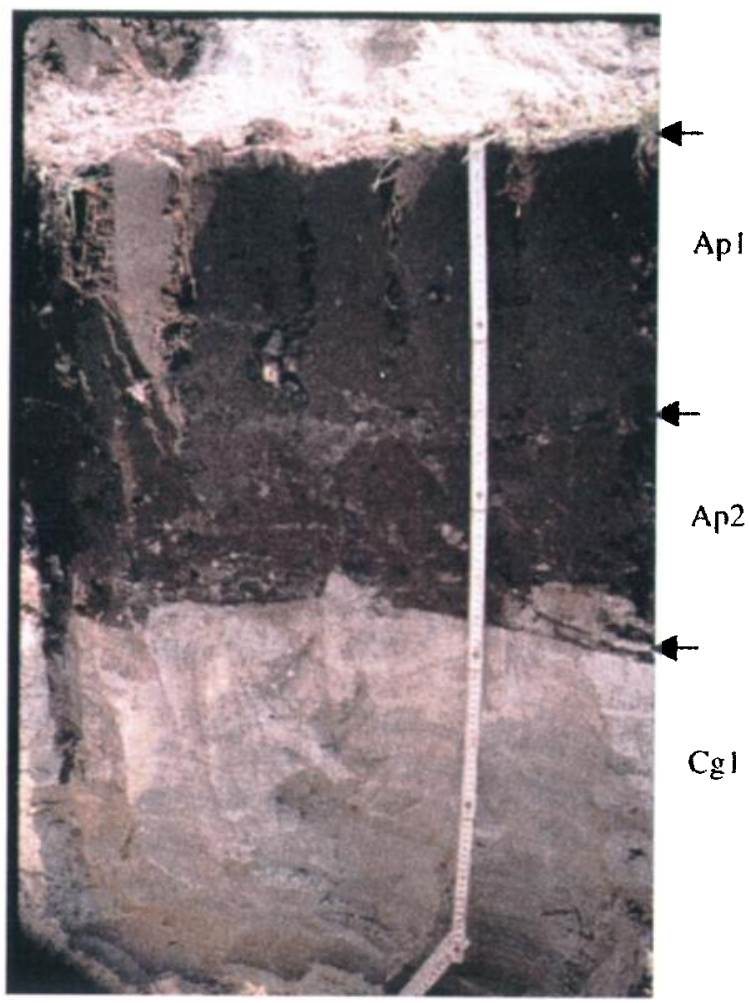

Lamellic Arenosol

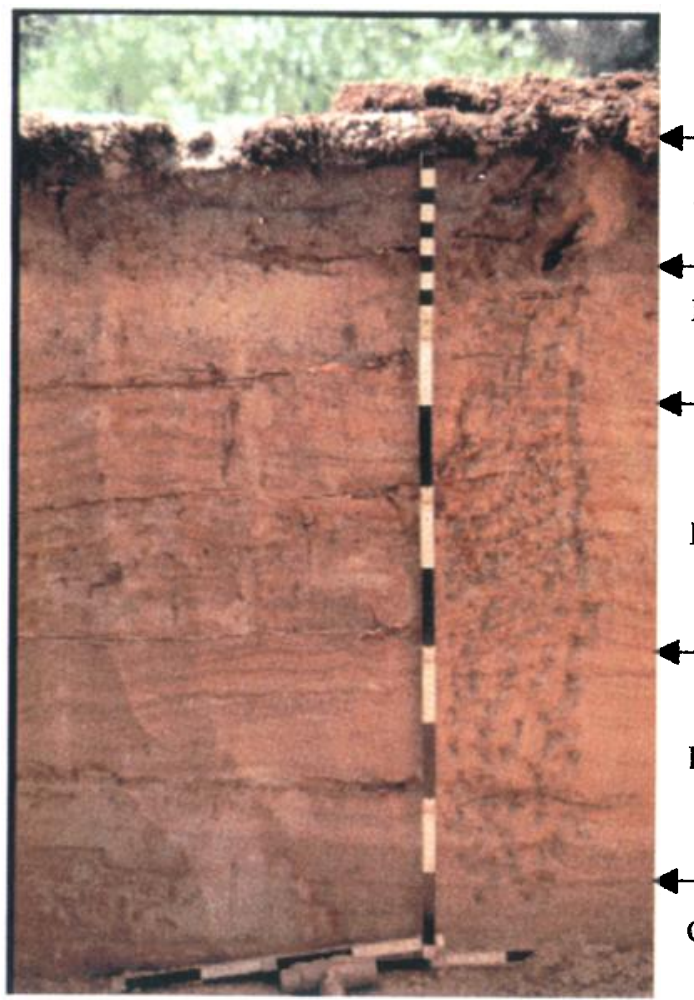

Haplic Podzol

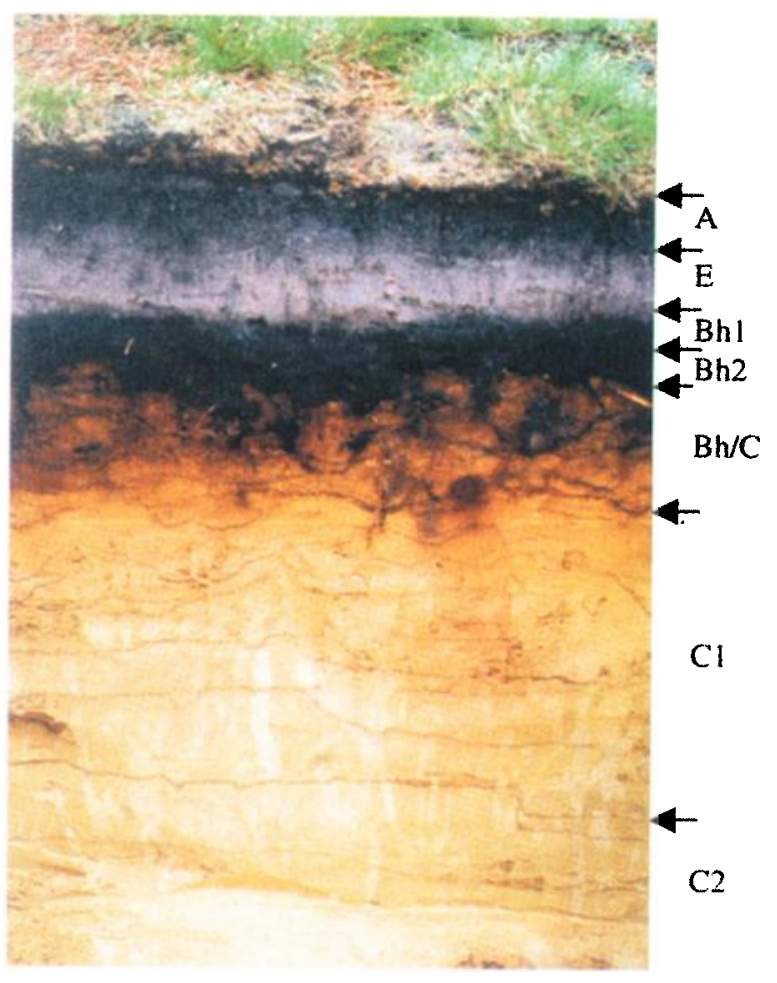

Lamelli-Luvic Arenosol (Eutric)

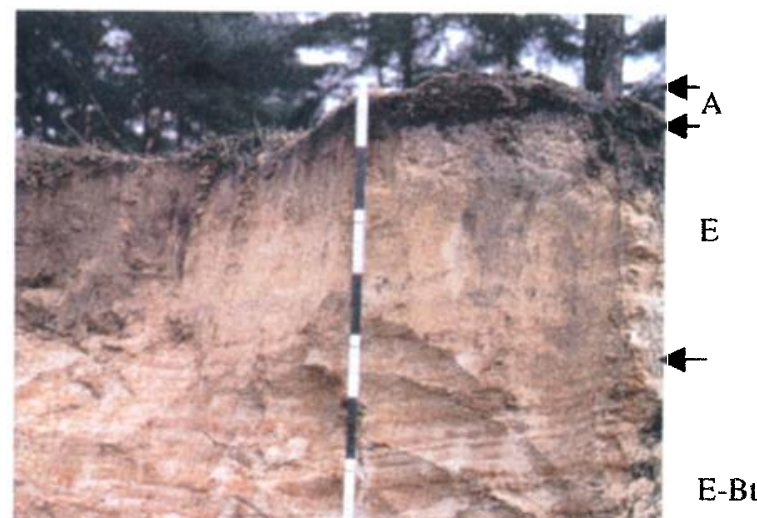

E-Btg

Plate 1. Pictures of soil profiles. 
Eutric Regosol

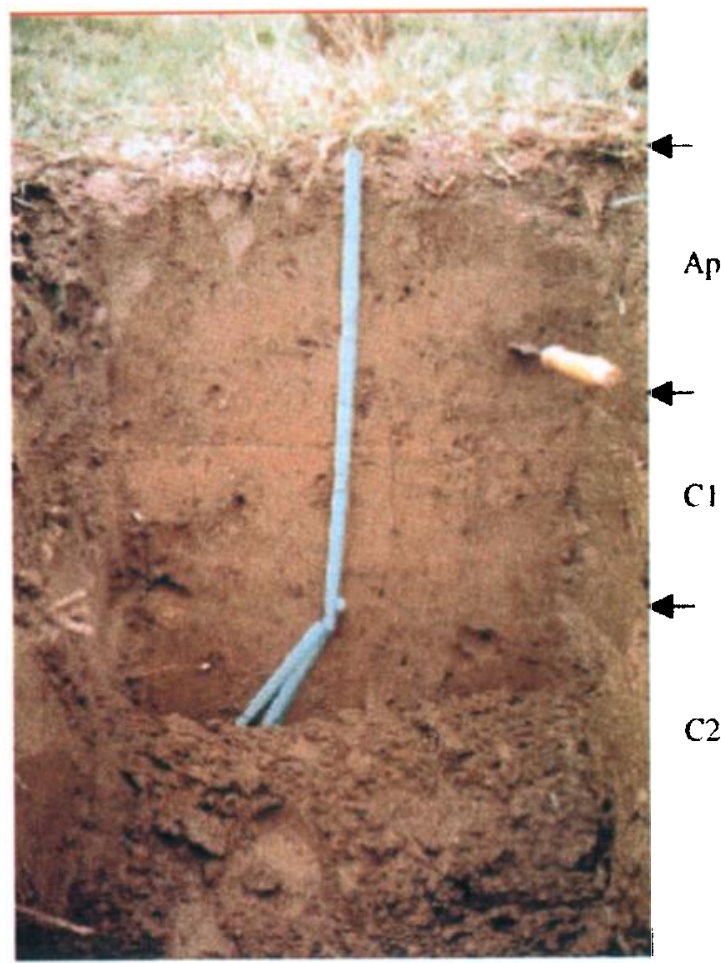

Eutnc Luvisol

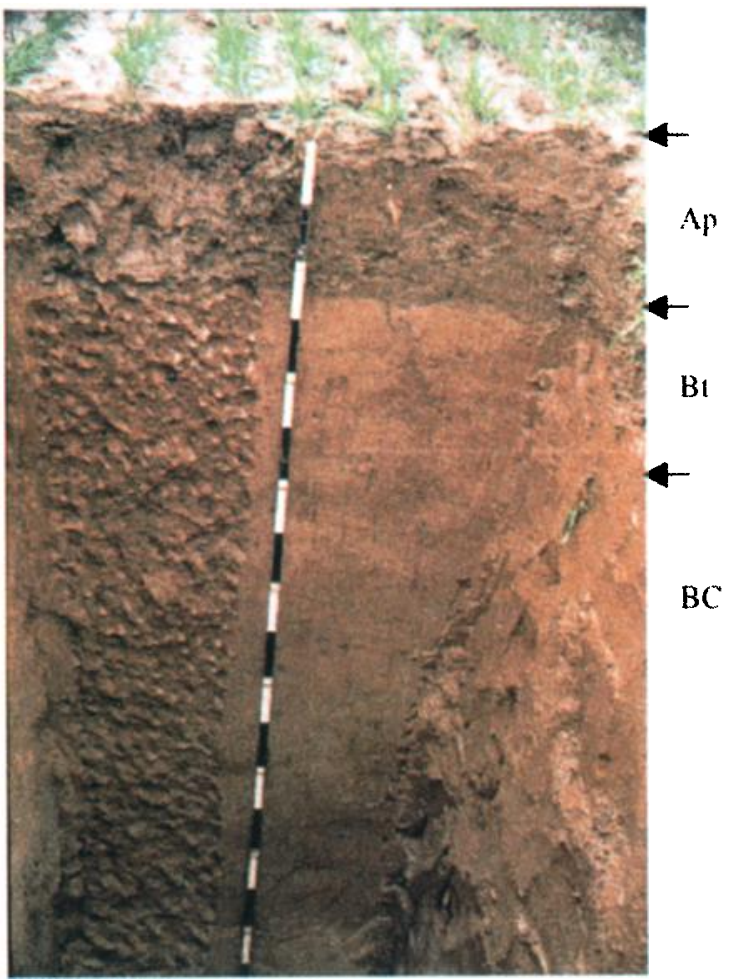

Silti-Stagnic Albeluvisol

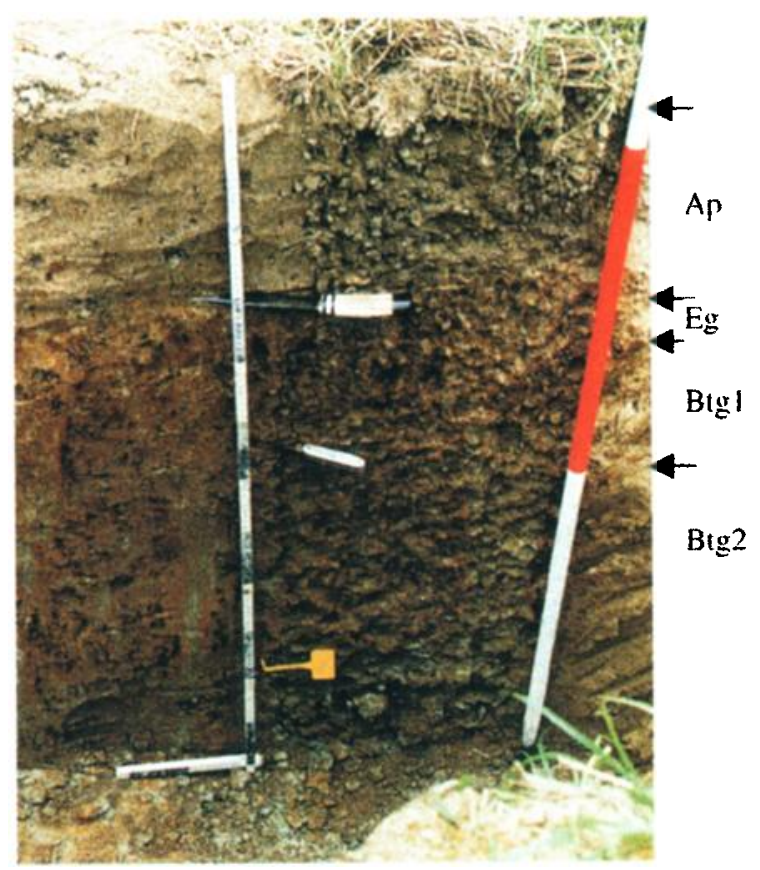

Plate 1. (continued) 
Table 1. Texture, Organic Carbon Content, and Bulk Density for the Soils Used in Leaching Experiments

\begin{tabular}{|c|c|c|c|c|c|c|}
\hline Horizon & Depth, cm & Clay, $\mathrm{g} \mathrm{kg}^{-1}$ & Silt, $\mathrm{g} \mathrm{kg}^{-1}$ & Sand, $\mathrm{g} \mathrm{kg}^{-1}$ & $\begin{array}{l}\text { Organic C } \\
\mathrm{g} \mathrm{kg}^{-1}\end{array}$ & $\begin{array}{l}\text { Bulk Density, } \\
\qquad \mathrm{g} \mathrm{cm}^{-3}\end{array}$ \\
\hline \multicolumn{7}{|c|}{ Gleyi-Plaggic Anthrosol (Arenic) } \\
\hline Ap1 & $0-30$ & 50 & 100 & 850 & 19.8 & 1.62 \\
\hline Ap2 & $30-56$ & 55 & 109 & 836 & 17.4 & 1.65 \\
\hline $\mathrm{Cg} 1$ & $56-100$ & 45 & 113 & 842 & 2.3 & 1.74 \\
\hline \multicolumn{7}{|c|}{ Haplic Podzol } \\
\hline A & $0-7$ & 1 & 3 & 996 & 3.65 & 1.31 \\
\hline $\mathbf{E}$ & $7-15$ & 2 & 4 & 994 & 0.78 & 1.59 \\
\hline Bh1 & $15-23$ & 11 & 11 & 978 & 3.03 & 1.3 \\
\hline $\mathrm{Bh} 2$ & $23-28$ & 15 & 13 & 972 & 1.23 & 1.38 \\
\hline $\mathrm{Bh} / \mathrm{C}$ & $28-38$ & 14 & 2 & 985 & 0.55 & 1.41 \\
\hline $\mathrm{C} 1$ & $38-49$ & 8 & 7 & 985 & 0.3 & 1.52 \\
\hline $\mathrm{C} 2$ & $49-77$ & 2 & 3 & 994 & 0.13 & 1.56 \\
\hline \multicolumn{7}{|c|}{ Lamellic Arenosol } \\
\hline Ap & $0-15$ & 63 & 48 & 889 & 44.5 & 0.84 \\
\hline$E$ & $15-33$ & 30 & 65 & 905 & 3.5 & 1.52 \\
\hline E-Btg1 & $33-60$ & 33 & 74 & 893 & 1.5 & 1.65 \\
\hline E-Btg2 & $60-90$ & 40 & 94 & 866 & 1.3 & 1.72 \\
\hline $\mathrm{Cg}$ & $90-100$ & 29 & 27 & 944 & 1.0 & 1.70 \\
\hline \multicolumn{7}{|c|}{ Lamelli-Luvic Arenosol (Eutric) } \\
\hline Ap1 & $0-30$ & 90 & 292 & 618 & 22 & 1.48 \\
\hline Ap2 & $30-48$ & 85 & 322 & 593 & 17 & 1.56 \\
\hline$E$ & $48-75$ & 82 & 386 & 532 & 5 & 1.48 \\
\hline E-Btg & $75-100$ & 74 & 390 & 536 & 4 & 1.47 \\
\hline \multicolumn{7}{|c|}{ Eutric Regosol } \\
\hline Ap & $0-25$ & 127 & 476 & 397 & 6 & 1.42 \\
\hline Ci & $25-55$ & 166 & 434 & 400 & 3 & 1.54 \\
\hline $\mathrm{C} 2$ & $55-100$ & 218 & 581 & 201 & 4 & 1.52 \\
\hline \multicolumn{7}{|c|}{ Eutric Luvisol } \\
\hline Ap & $0-28$ & 156 & 657 & 187 & 15.7 & 1.44 \\
\hline $\mathrm{Bt}$ & $28-54$ & 250 & 489 & 261 & 14.5 & 1.54 \\
\hline $\mathrm{BC}$ & $54-100$ & 207 & 568 & 225 & 10.5 & 1.61 \\
\hline \multicolumn{7}{|c|}{ Silti-Stagnic Albeluvisol } \\
\hline Ap & $0-30$ & 189 & 664 & 147 & 17 & $\mathrm{na}^{\mathrm{a}}$ \\
\hline Eg & $30-40$ & 183 & 666 & 151 & 9 & na \\
\hline Btg1 & $40-60$ & 233 & 613 & 154 & 4 & na \\
\hline Btg2 & $60-100$ & 236 & 561 & 203 & 5 & na \\
\hline
\end{tabular}

${ }^{a}$ Not available.

creasing $x$, which indicates that most of the solute dispersion is observed when concentrations are averaged over a relatively small horizontal scale. We conclude that for these two soils, dispersivities derived from tracer experiments in undisturbed soil columns with dimensions of the "small" or "large" lysimeters are of similar magnitude than those obtained from field experiments. For instance, leaching experiments were carried out in two "small lysimeters" taken from the Regosol under similar conditions as those for the field experiment. The $\lambda_{L}$ derived from BTCs measured in these lysimeters were similar to dispersivities derived from field-scale averaged BTCs (i.e., $\lambda_{L}(z=100 \mathrm{~cm})=11.1 \mathrm{~cm}$ in the small lysimeters, and $\lambda_{L}(z=90 \mathrm{~cm})=6.4-8.6 \mathrm{~cm}$ in the field experiment $)$.

It should be noted that horizon thickness in both soils did not change considerably along the transect. In soils with spatial variations of horizon thickness, important horizontal redistribution of water and solutes may occur over a larger horizontal scale [e.g., van Wesenbeeck and Kachanoski, 1994; Ward et al., 1995]. Neither lenses of coarse-textured material, which could act as capillary barriers, nor highly compacted layers such as plow layers, which obstruct flow, were observed in these soils. Above such flow barriers, water and solutes can be horizontally redistributed over significant horizontal distances [e.g., Kung, 1990a, 1990b].

\subsection{Vertical-Scale Efiect and Mixing Regime}

Figure 4 shows $\lambda_{L}$ as a function of depth $z$ in the six different soils. Also shown are the coefficients of determination $R^{2}$ between $\log _{10}(z)$ and $\log _{10}\left(\lambda_{L}\right)$. A $\log _{10}$ transformation was done to stabilize the variance of the residuals so that statistical inference about $R^{2}$ is meaningful [Neter et al., 1990].

Based on the behavior of $\lambda_{L}$ with $z$, two groups of soils can be defined: one soil group (i.e., Anthrosol, Regosol, Luvisol, and Albeluvisol) in which $\lambda_{L}$ increases significantly with $z$, indicating incomplete lateral solute mixing, and one group (i.e., both Arenosols, Podzol, and the Regosol) in which $\lambda_{L}$ remains fairly constant or even decreases with $z$, indicating complete lateral solute mixing. The group to which a soil belongs may depend on the flow rate during the leaching experiment. For instance, at a low leaching flow rate $\left(J_{w}=1.3 \mathrm{~cm}\right.$ $\left.\mathrm{d}^{-1}\right), \lambda_{L}$ remained constant with $z$ in the Regosol whereas $\lambda_{L}$ increased with $z$ at higher flow rates (e.g., in Figure $4, J_{w}=7.1$ $\mathrm{cm} \mathrm{\textrm {d } ^ { - 1 }}$ ). This indicates that the lateral solute mixing regime may change with changing flow conditions in the soil. Figure 4 
Table 2. Parameters of Hydraulic Functions $\theta(h)^{\mathbf{a}}$ and $K(h)^{\mathbf{b}}$ for Different Soils Investigated ${ }^{\mathbf{c}}$

\begin{tabular}{|c|c|c|c|c|c|c|c|c|c|}
\hline & $\theta_{r}$ & $\theta_{s}$ & $\alpha, \mathrm{cm}^{-1}$ & $n$ & $m$ & $K_{s}, \mathrm{~cm} \mathrm{~d}^{-1}$ & $B$ & $N$ & \\
\hline \multicolumn{10}{|c|}{ Gleyi-Plaggic Anthrosol (Arenic) } \\
\hline Ap1 & 0.012 & 0.354 & 0.001 & 1.09 & 1 & 15.4 & 0.144 & 1.66 & \\
\hline Ap2 & 0.006 & 0.361 & 0.0011 & 0.97 & 1 & 2.0 & 0.02 & 2.03 & \\
\hline $\mathrm{Cg} 1$ & 0.028 & 0.292 & 0.01 & 1.67 & 1 & 27.6 & 0.055 & 2 & \\
\hline \multicolumn{10}{|c|}{ Lamelli-Luvic Arenosol (Eutric) } \\
\hline Ap1 & 0.052 & 0.418 & 0.0028 & 1.04 & 1 & 49.2 & 0.095 & 2.26 & \\
\hline Ap2 & 0.049 & 0.385 & 0.0034 & 1.1 & 1 & 74.4 & 0.135 & 2.33 & \\
\hline $\mathrm{E}$ & 0.063 & 0.374 & 0.0067 & 2.57 & 1 & 39.1 & 0.03 & 3.67 & \\
\hline E-Btg & 0.051 & 0.371 & 0.0065 & 1.96 & 1 & 43.6 & 0.038 & 2.9 & \\
\hline \multicolumn{10}{|c|}{ Eutric Luvisol } \\
\hline Ap & 0.075 & 0.417 & 0.0018 & 0.8 & 1 & 1.2 & 0.043 & 1.56 & \\
\hline $\mathrm{Bt}$ & 0.113 & 0.416 & 0.0012 & 0.55 & 1 & 7.1 & 3.581 & 1.12 & \\
\hline $\mathrm{BC}$ & 0.123 & 0.398 & 0.0013 & 0.69 & 1 & 4.9 & 1.851 & 1.15 & \\
\hline & $\theta_{r}$ & $\theta_{s}$ & $\alpha, \mathrm{cm}^{-1}$ & $n$ & $m$ & $K_{s}, \mathrm{~cm} \mathrm{~d}^{-1}$ & $\alpha, \mathrm{cm}^{-1}$ & $n$ & $l$ \\
\hline \multicolumn{10}{|c|}{ Haplic Podzol } \\
\hline A & 0.065 & 0.48 & 0.016 & 1.94 & 0.48 & 93 & 0.016 & 1.94 & 0.5 \\
\hline $\mathrm{E}$ & 0.035 & 0.42 & 0.015 & 3.21 & 0.69 & 311 & 0.015 & 3.21 & 0.5 \\
\hline Bh1 & 0.042 & 0.47 & 0.016 & 1.52 & 0.34 & 39 & 0.016 & 1.52 & 0.5 \\
\hline $\mathrm{Bh} 2$ & 0.044 & 0.46 & 0.028 & 2.01 & 0.50 & 860 & 0.028 & 2.01 & 0.5 \\
\hline $\mathrm{Bh} / \mathrm{C}$ & 0.039 & 0.46 & 0.023 & 2.99 & 0.67 & 1198 & 0.023 & 2.99 & 0.5 \\
\hline C1 & 0.03 & 0.42 & 0.021 & 3.72 & 0.73 & 1218 & 0.021 & 3.72 & 0.5 \\
\hline $\mathrm{C} 2$ & 0.021 & 0.39 & 0.021 & 4.33 & 0.77 & 1206 & 0.021 & 4.33 & 0.5 \\
\hline \multicolumn{10}{|c|}{ Eutric Regosol: All Horizons (Scaled $\theta(h)$ and $K(\theta)$ ) } \\
\hline & 0.001 & 0.4 & 0.011 & 1.29 & 0.22 & 38 & 0.026 & 1.43 & 0.5 \\
\hline \multicolumn{10}{|c|}{ Silti-Stagnic Albeluvisol } \\
\hline Ap, $0-0.1 \mathrm{~m}$ & 0.025 & 0.401 & 0.019 & 1.29 & 0.22 & 27.5 & 0.029 & 1.12 & 1.17 \\
\hline Ap, $0.1-0.3 \mathrm{~m}$ & 0.019 & 0.396 & 0.017 & 1.27 & 0.21 & 38.8 & 0.044 & 1.24 & 5.16 \\
\hline $\mathrm{Eg}, 0.3-0.5 \mathrm{~m}$ & 0.003 & 0.391 & 0.017 & 1.24 & 0.19 & 1.9 & 0.035 & 1.38 & 2.83 \\
\hline Btg1, 0.5-0.7 m & 0.037 & 0.4 & 0.033 & 1.27 & 0.21 & 79.6 & 0.032 & 1.31 & 1.89 \\
\hline Btg2, 0.7-0.9 m & 0.024 & 0.394 & 0.044 & 1.24 & 0.2 & 869 & 0.082 & 1.21 & -1.69 \\
\hline Btg2, 0.9-1 m & 0.004 & 0.396 & 0.012 & 1.22 & 0.18 & 225 & 0.202 & 1.43 & -0.9 \\
\hline
\end{tabular}

${ }^{\mathrm{a}} \theta(h)=\theta_{r}+\left(\theta_{s}-\theta_{r}\right) /\left\{\left[1+(\alpha h)^{n}\right]^{m}\right\}[$ van Genuchten, 1980].

${ }^{\mathrm{b}} K(h)=K_{s} /\left[1+(B h)^{N}\right]$ [Gardner, 1958] is used for Gleyi-Plaggic Anthrosol (Arenic), Lamelli-Luvic Arenosol (Eutric), and Eutric Luvisol, while $K(h)=K_{s}\left\{1-(\alpha h)^{n-1}\left[1+(\alpha h)^{n}\right]^{1 / n-1}\right\}^{2} /\left\{\left[1+(\alpha h)^{n}\right]^{l(1-1 / n)}\right\}$ [van Genuchten, 1980] is used for Haplic Podzol, Eutric Regosol, and Silti-Stagnic Albeluvisol.

${ }^{c}$ Lamellic Arenosol not available.

further illustrates that $\lambda_{L}$ may increase by more than a factor 10 over a travel depth of $1 \mathrm{~m}$. The vertical scale of the transport experiment or the length of the soil columns is hence much more important than the horizontal scale of the experiment for the observed solute dispersion in these soils.

The lateral solute mixing regime in a specific soil could be linked to morphological features of the soil profile. In the Podzol the apparent dispersivity reaches a constant value below the top of the spodic horizon. This indicates that this cemented layer with a high bulk density and lower conductivity (see Table 2 and Figure 4) enhances lateral solute mixing. The horizontal bands with a finer texture which are alternated with layers with a coarser texture in the lamellic illuvial clay horizon of the Lamellic Arenosols (see Plate 1) can promote lateral solute mixing and, hence, a convective-dispersive transport regime. Roth et al. [1991] also attributed the convectivedispersive transport regime of the main solute plume, which was observed in their field-scale experiment, to lateral solute mixing at the interfaces between different soil layers. Dye tracer experiments in artificial soil columns with coarsetextured layers alternated with finer-textured layers indicated that lateral mixing is enhanced at the interface between a coarse-textured layer overlying a finer-textured layer [Koch and Flühler, 1994]. On the other hand, funneling of streamlines and formation of preferential flow paths occurs when the streamlines pass from the fine to the coarse material [Koch and Flühler, 1994]. However, the next interface from coarse to finer material induces again lateral mixing, so that the travel distance or travel time in preferential flow paths without lateral mixing remains small for a small vertical distance between the horizontal bands with a finer texture. Also, the formation of unstable wetting fronts and preferential flow paths under transient flow conditions is largely reduced by alternated coarse and fine horizontal soil layers [Wang et al., 1998]. Finally, even if the horizontal stratification of the soil profile does not influence the flow regime, it indicates that flow in the Lamellic Arenosols is relatively uniform since the layers are formed by illuviation of clay colloids. If flow were very heterogeneous, horizontal illuvial horizons could not have developed in the soil profile.

On the other hand, vertical structures or "tongues" of coarser textured material in the illuvial clay horizon of the Albeluvisol could act as preferential flow paths, reduce the lateral mixing of solutes, and explain the stochastic-convective mixing regime observed in this soil. Dye tracer experiments in a soil with a similar degraded illuvial clay horizon [Gähwiller, 


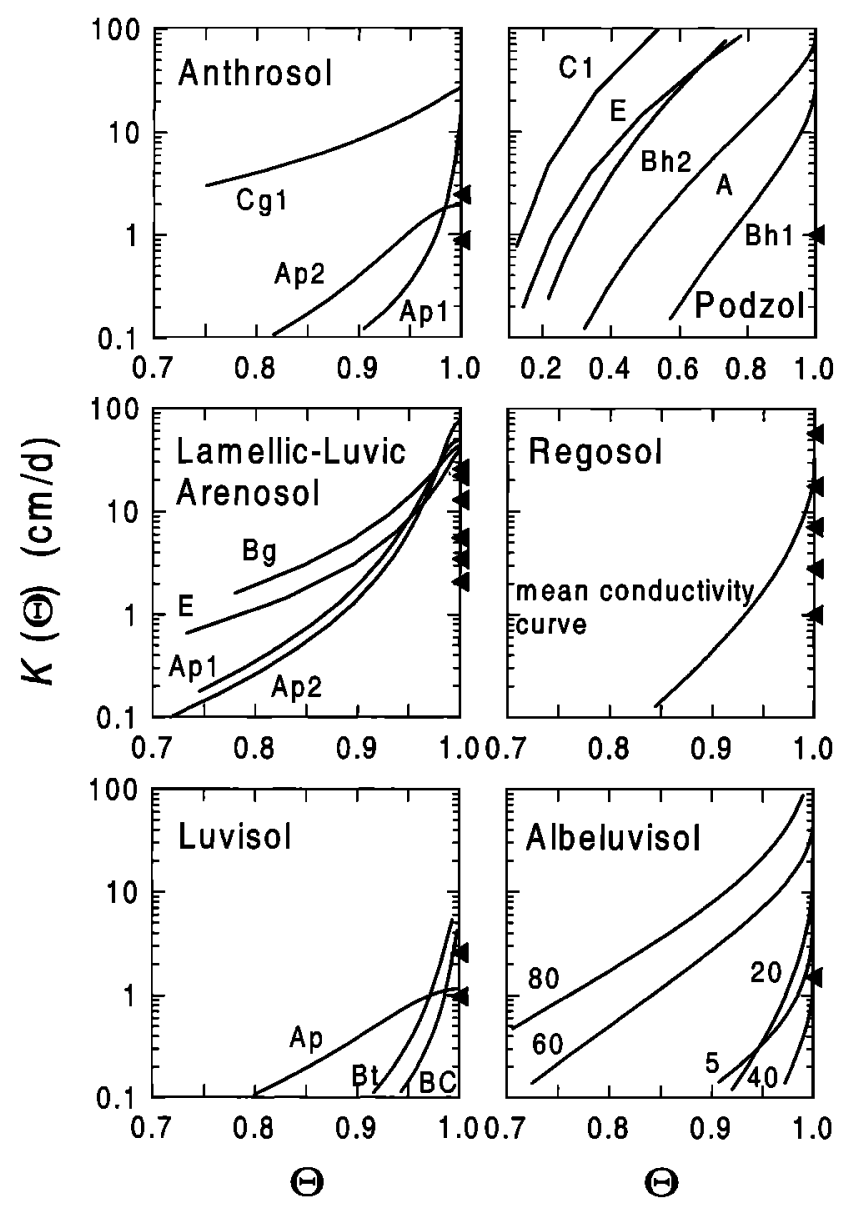

Figure 2. Hydraulic conductivity $K$ as a function of the relative water saturation, $\Theta=\left(\theta-\theta_{r}\right) /\left(\theta_{s}-\theta_{r}\right)$, in the different horizons of the soil profiles. Labels indicate the soil horizons (for the Albeluvisol the depth of the soil layer where samples were taken is indicated). Triangles indicate the effective flow rates $J_{\text {weff }}$ (equation (7)) at the bottom of the soil columns during the leaching experiments.

1997] clearly indicated that the dye tracer was preferentially transported through these tongues.

In the Anthrosol, besides the abrupt boundary between the dark plaggen horizon and the white, leached out sand below, no morphological structures were visible. However, the plaggen horizon was water-repellent when dry. Small spatial variations in water repellency can result in considerable horizontal redistribution of water and solutes into locations where the water repellency is relatively low [Ritsema and Dekker, 1995]. This mechanism leads to preferential flow with less lateral solute mixing and, hence, a stochastic-convective mixing regime. In the underlying homogeneous sand horizon, redistribution by capillary forces of water and solutes out of the preferential flow paths is small, and no banded horizontal structures, which could promote horizontal redistribution, are observed in this soil. Ritsema et al. [1998] showed that in waterrepellent soils the preferential flow paths are formed at the same locations when the soil is wetted. They suggested that because of leaching of water-repellent organic substances from locations where the preferential flow paths are generated, there is a positive feedback mechanism which fixes the locations of flow paths and induces preferential flow.

Finally, the lack of lateral solute mixing and the stochastic- convective transport process in the Regosol and Luvisol soils can be attributed to fast solute transport through wormholes, root channels, and large interaggregate cracks bypassing the solution in the soil matrix. Experiments with dye tracers in the Regosol indicated a continuous network of macropores down to a depth of $1 \mathrm{~m}$ in the soil profile [Vanderborght et al., 2000a]. Macropore flow is especially important when the hydraulic conductivity of the soil matrix is small because of the fine texture of the soil material, since flow and transport through macropores are generated at flow rates that exceed the hydraulic conductivity of the soil matrix. For lower flow rates, flow and transport occur primarily through the smaller pores of the soil matrix, and the macropores remain empty, so that the applied tracer solution is better laterally mixed across all conducting pores. The shift in mixing regime with changing flow rate was clearly seen in the Regosol, with a convectivedispersive transport process at lower flow rates changing to a stochastic-convective process at higher flow rates.

The previous discussion illustrates that morphological features in the soil profile can serve as indicators of a certain mixing regime. However, in the same profile, indicators of the two opposite mixing regimes, stochastic-convective and convective-dispersive, might be present, making the prediction of the mixing regime from morphological features ambiguous. This ambiguity partly results from representing the entire spectrum of mixing regimes by two classes that correspond with the extremes of the spectrum, i.e., no lateral mixing at all (stochastic-convective) versus complete lateral mixing (convectivedispersive). For instance, the vertical patterns in the E-Btg horizon of Lamelli-Luvic Arenosol and the $\mathrm{C} 1$ and $\mathrm{C} 2$ horizons of the Podzol would suggest a stochastic-convective process. On the other hand, the horizontal bands in the Lamelli-Luvic Arenosol and the cemented spodic horizon in the Podzol promote lateral mixing and are indicators of the convectivedispersive process that we observed in all leaching experiments in these soils. Therefore, in our experiments the indicators of lateral mixing were more strongly related to the mixing regime than the indicators of preferential flow. Yet more research is definitely required to identify indicators that are more strongly related to the mixing regime and under which conditions.

\subsection{Effect of Flow Rate on Solute Dispersion}

Figure 5 shows the observed breakthrough curves in the Regosol at a depth of $72.5 \mathrm{~cm}$ under steady state and transient flow conditions. In both the steady state and transient flow experiments, $2.8 \mathrm{~cm}$ of water were infiltrated every day $\left(\left\langle J_{w}\right\rangle=\right.$ $2.8 \mathrm{~cm} \mathrm{~d}^{-1}$, equation (6)). However, in the transient experiment, this amount of water was infiltrated daily during a period of 3 hours with a constant infiltration rate of $22.2 \mathrm{~cm} \mathrm{~d}^{-1}$. As a consequence, the effective flow rate at the observation depth was much larger for the transient $\left(J_{w \text { eff }}=17.6 \mathrm{~cm} \mathrm{~d}^{-1}\right.$, equation (7)) than for the steady state experiment $\left(J_{w \text { eff }}=\left\langle J_{w}\right\rangle=\right.$ $2.8 \mathrm{~cm} \mathrm{~d}^{-1}$ ). Figure 5 clearly illustrates that the solute dispersion is much larger under transient than under steady state flow conditions and that $J_{w e f f}$ rather than $\left\langle J_{w}\right\rangle$ determines solute dispersion. In all soils in which we did leaching experiments at different flow rates (i.e., all soils except the Albeluvisol, the Podzol, and the Lamellic Arenosol) we found that $\lambda_{L}$ increased with increasing $J_{\text {weff }}$ In Figure $6, \log _{10}\left(\lambda_{L}\right)$ in the Lamelli-Luvic Arenosol and in the Regosol are plotted versus $\log _{10}\left(J_{\text {weff }}\right)$. This plot shows that in both soils, $\lambda_{L}$ may increase by a factor 10 with increasing $J_{\text {weff }}$. Therefore, besides the vertical scale of the experiment, also the boundary condi- 
Table 3. Setup of Leaching Experiments: Size of the Soil Sample, Water Application Frequency and Application Time, Leaching Rate (Time-Averaged, $\left\langle J_{w}\right\rangle$, and Effective, $J_{\text {weff }}$, Flow Rate at the Bottom of the Lysimeter), Initial Solute Concentration $C_{1 \mathrm{n}}$, and Tracer Concentration in Displacing Solution $C_{0}$

\begin{tabular}{|c|c|c|c|c|c|}
\hline Soil & Sample Size & $\begin{array}{l}\text { Water Application } \\
\text { Frequency, } d^{-1} \\
\text { (Application } \\
\text { Time, hours) }\end{array}$ & $\left\langle J_{w}\right\rangle\left(J_{w e f f}\right), \mathrm{cm} \mathrm{d}^{-1}$ & $\begin{array}{l}C_{\mathrm{in}}, M \\
\mathrm{CaCl}_{2}\end{array}$ & $\begin{array}{l}C_{0}, M \\
\mathrm{CaCl}_{2}\end{array}$ \\
\hline Anthrosol & large lysimeter & $1(\approx 0.1)$ & $0.5(0.9)$ & $\mathrm{na}^{\mathrm{a}}$ & 0.0504 \\
\hline Anthrosol & large lysimeter & $1(\approx 0.1)$ & $1.0(2.5)$ & na & 0.0115 \\
\hline Podzol & large lysimeter & continuous & 1.0 & 0.005 & $0.05^{\mathrm{b}}$ \\
\hline $\begin{array}{l}\text { Lamellic } \\
\text { Arenosol }\end{array}$ & large lysimeter & continuous & 30 & na & 0.0204 \\
\hline $\begin{array}{l}\text { Lamelli-Luvic } \\
\text { Arenosol }\end{array}$ & large lysimeter & $1(\approx 0.1)$ & $1.0(3.5)$ & na & 0.0504 \\
\hline $\begin{array}{c}\text { Lamelli-Luvic } \\
\text { Arenosol }\end{array}$ & small lysimeter & continuous & $1.7-2.6$ & 0.0054 & 0.0587 \\
\hline $\begin{array}{l}\text { Lamelli-Luvic } \\
\text { Arenosol }\end{array}$ & small lysimeter & continuous & $5.4-5.7$ & 0.0054 & 0.0587 \\
\hline $\begin{array}{c}\text { Lamelli-Luvic } \\
\text { Arenosol }\end{array}$ & small lysimeter & continuous & 13.0 & na & 0.0587 \\
\hline $\begin{array}{c}\text { Lamelli-Luvic } \\
\text { Arenosol }\end{array}$ & small lysimeter & $0.667(2.5)$ & $2.5(5.8)-2.3(10.3)$ & 0.0587 & 0.0055 \\
\hline $\begin{array}{c}\text { Lamelli-Luvic } \\
\text { Arenosol }\end{array}$ & small lysimeter & $1(4.5)$ & $5.7(13.3)-5.7(22.0)$ & 0.0587 & 0.0054 \\
\hline $\begin{array}{c}\text { Lamelli-Luvic } \\
\text { Arenosol }\end{array}$ & small lysimeter & $1(7.5)$ & $13.0(21.6)-12.9(25.7)$ & 0.0587 & 0.0054 \\
\hline Regosol & field & continuous & 2.84 & na & $0.5952^{c}$ \\
\hline Regosol & small lysimeter & continuous & 1.3 & 0.0054 & 0.0234 \\
\hline Regosol & small lysimeter & continuous & 2.8 & 0.0055 & 0.0467 \\
\hline Regosol & small lysimeter & continuous & $6.8-7.4$ & na & 0.0467 \\
\hline Regosol & small lysimeter & $1(3)$ & $2.8(17.6)$ & 0.048 & 0.0054 \\
\hline Regosol & small lysimeter & $1(3)$ & $8.2(56.9)$ & 0.0467 & 0.0054 \\
\hline Luvisol & large lysimeter & $1(\approx 0.1)$ & $0.5(0.98)$ & na & 0.0504 \\
\hline Luvisol & large lysimeter & $1(\approx 0.1)$ & $1.0(2.6)$ & na & 0.0115 \\
\hline Albeluvisol & field & continuous & 1.5 & na & $0.5441^{d}$ \\
\hline
\end{tabular}

${ }^{a}$ Not available.

'Solute pulse was applied. The pulse duration was 1 day.

'Solute pulse was applied. The pulse duration was 5.7 hours.

dSolute pulse was applied. The pulse duration was 8.0 hours.

tions that determine the effective flow rate in the soil are important to interpret dispersion coefficients derived from leaching experiments in different soils.

\subsection{Relation Between $\lambda_{L}$ and $K(\theta)$}

In Figure 7, $\lambda_{L}$ derived from BTCs observed at $1 \mathrm{~m}(0.9 \mathrm{~m}$ for the Albeluvisol) below the soil surface are plotted versus

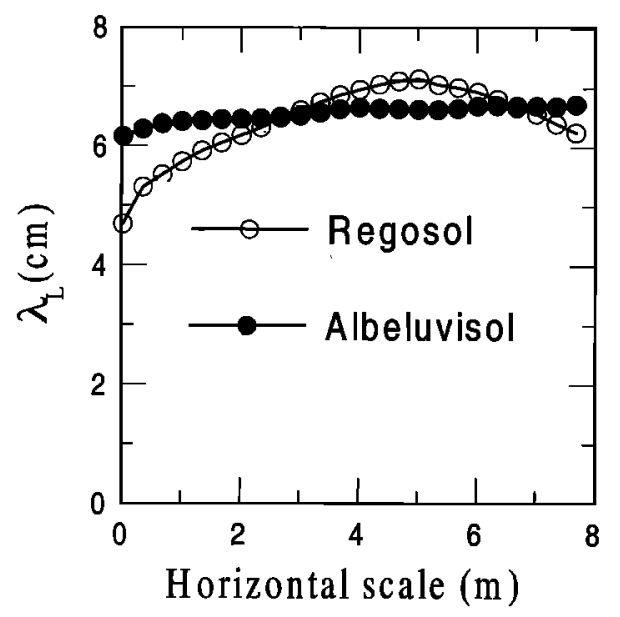

Figure 3. Effect of the horizontal scale of the leaching experiment on the observed dispersivity $\lambda_{L}$ in the Regosol and Albeluvisol.
$\mathrm{CV}_{u}^{2}\left(\theta, J_{w}\right) \cdot \mathrm{CV}_{u}^{2}\left(\theta, J_{w}\right)\left(\mathrm{CV}_{u}^{2}\left(\theta, J_{w e f f}\right)\right.$ for the transient experiments) was calculated from the measured $K(\theta)$ curves in each soil horizon using (11). Except for the Anthrosol, $\mathrm{CV}_{u}^{2}$ was arithmetically averaged across all soil layers and weighted according to the thickness of a given soil layer. The weighted arithmetic average corresponds to a weighted arithmetic average of the dispersivities in the different soil layers. It can be shown for a convective-dispersive transport process and uniform water content in the soil profile that this average corresponds to the apparent dispersivity derived from a BTC at the bottom of the profile. Vanderborght et al. [2000a] show that changes in water content with depth have only a minor impact on the apparent dispersivity, so that a uniform water content can be assumed even when the water content changes with depth. In the Anthrosol, $\mathrm{CV}_{u}^{2}$ was calculated from the $K(\theta)$ curve of the top layer only. The $\mathrm{CV}_{u}^{2}$ values for the underlying layers were considerably smaller, and including them led to a too small $\mathrm{CV}_{u}^{2}$ for the $\lambda_{L}$ observed in this soil compared to $\lambda_{L}\left(\mathrm{CV}_{u}^{2}\right)$ in the other soils. The $\lambda_{L}\left(\mathrm{CV}_{u}^{2}\right)\left(\lambda_{L}=90-150 \mathrm{~cm}\right)$ for the highest effective flow rate in the Regosol $\left(J_{\text {weff }}=56.9\right.$ $\mathrm{cm} \mathrm{d}^{-1}$ ) was an outlier and was not included in Figure 7. For the Lamelli-Luvic Arenosol, $\lambda_{L}$ values were averaged over leaching experiments with similar $J_{\text {weff }}$. Figure 7 illustrates that much of the variability in $\lambda_{L}$ observed between different soil types and for different leaching regimes can be explained by the $K(\theta)$ relationship. Based on the coefficient of determination $R^{2}$, around $70 \%$ of the observed variation in $\lambda_{L}$ is ex- 

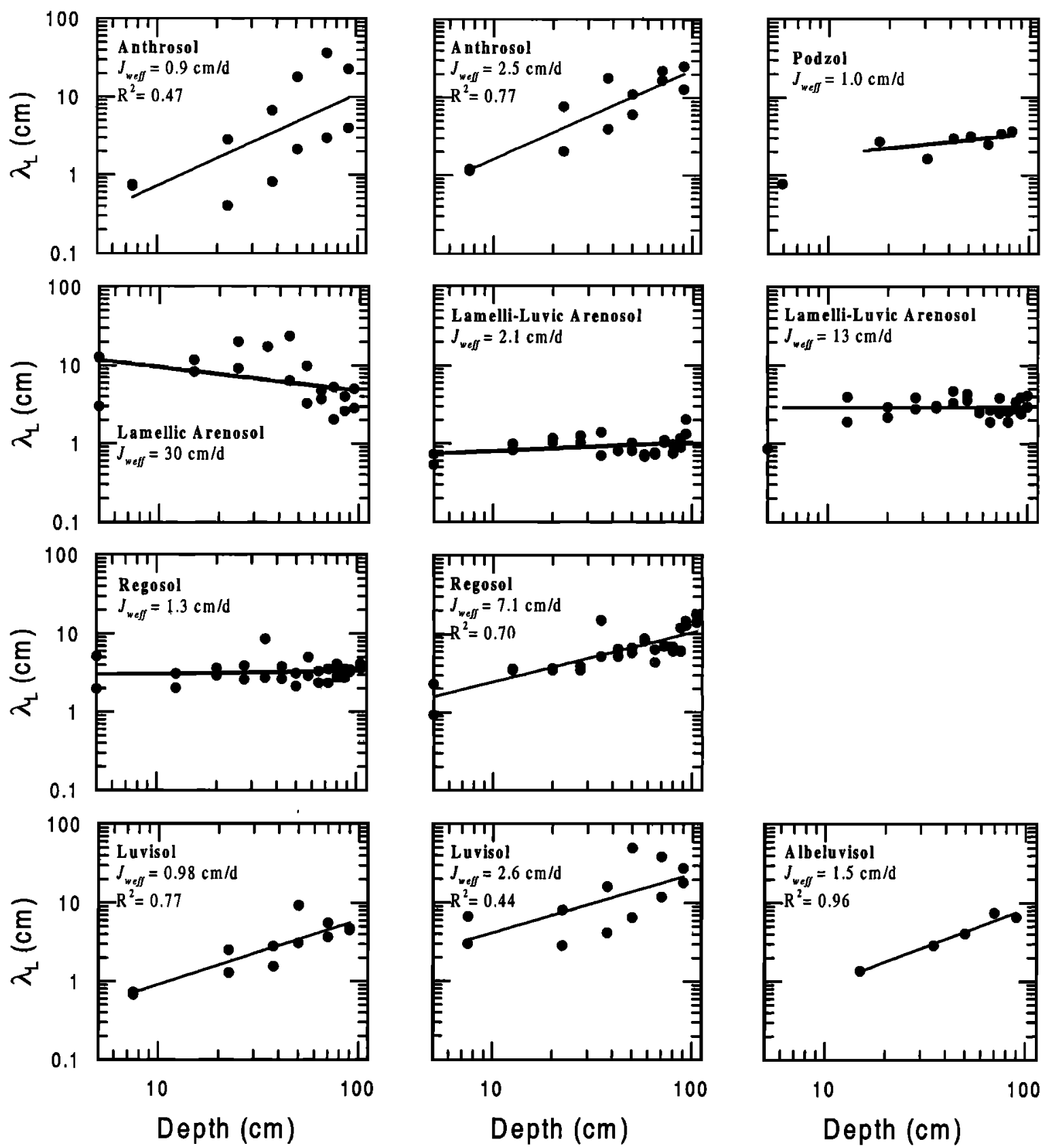

Figure 4. Dispersivity $\lambda_{L}$ derived from a breakthrough curve at a certain depth in the soil profile, as a function of depth $z$. ( $J_{w \text { eff }}$ is the effective flow rate during the leaching experiment, and $R^{2}$ is the coefficient of determination between $\log _{10}\left(\lambda_{L}\right)$ and $\log _{10}(z)$ and is only shown when $R^{2}$ is significantly larger than 0 .)

plained by $\mathrm{CV}_{u}^{2}$. However, the standard deviation of the residuals, $\sigma_{\text {res }}=7.8 \mathrm{~cm}$, is still rather large, and the parameters of the regression function are apparently merely fitting parameters without physical meaning. For instance, the negative intercept suggests a negative dispersivity when $\mathrm{CV}_{u}^{2} \rightarrow 0$. The slope of the regression line suggests a mixing length $\left(l^{*}=\right.$ $0.96 \mathrm{~cm}$ ), which is contradictory to the stochastic-convective transport regime observed in some soil types. The large $\sigma_{\text {res }}=$ $7.8 \mathrm{~cm}$ and the lack of physical meaning of the regression parameters obviously result from neglecting processes that define solute dispersion in soils. Not accounting for local solute mixing due to molecular diffusion leads to an overestimation of $\mathrm{CV}_{u}^{2}$ and, hence, an underestimation of $l^{*}$. Since $l^{*}$ is likely to depend on both the soil type and the flow rate, assuming a constant $l^{*}$ leads to additional "noise" in the relation between $\lambda_{L}$ and $\mathrm{CV}_{u}^{2}$. Furthermore, the effects of spatial variability in macroscopic hydraulic properties on solute dispersion are not accounted for by the multidomain conceptualization of the pore space, which considers only variations of solute velocities at the pore scale. For instance, the top layer of the Anthrosol is supposed to act as a funneling layer, in which macroscopic preferential flow paths and variability in solute advection velocity are generated. As a consequence, variations in advection velocity in the underlying soil layers are not primarily caused by variations in advection velocity at the pore scale. This could explain why the $\mathrm{CV}_{u}^{2}$ derived from the $K(\theta)$ of these layers is immaterial for $\lambda_{L}$ in this soil. 


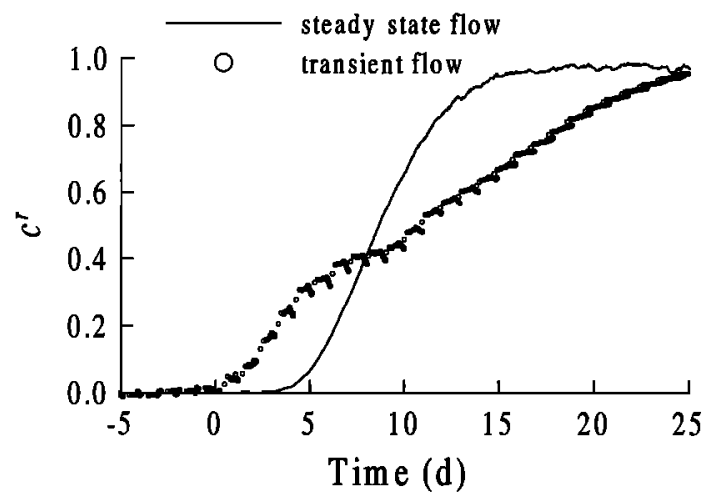

Figure 5. Breakthrough curves measured in the Regosol at $72.5 \mathrm{~cm}$ below the surface during steady state and transient flow. In the transient experiment, water was applied each day during a short application period whereas it was applied continuously in the steady state experiment. In both experiments the same amount of water was applied during 1 day. From Vanderborght et al. [2000a].

Finally, the hydraulic conductivity was described by a "unimodal" function, which assumes a unimodal pore size distribution. In macroporous soils, such a function may be insufficiently flexible to describe the hydraulic conductivity close to saturation, where the conductivity increases dramatically with increasing water saturation because of the activation of macropores [Durner, 1994]. Since $\mathrm{CV}_{u}^{2}$ depends on the slope of the $K(\theta)$ curve, $\mathrm{CV}_{u}^{2}$ is very sensitive to the description of $K(\theta)$ in a macroporous soil [e.g., Zurmühl and Durner, 1996]. This, in combination with the increase of $l^{*}$ when long continuous macropores are activated, could explain the outlying $\lambda_{L}\left(\mathrm{CV}_{u}^{2}\right)$ for the highest flow rate in the Regosol (not shown in Figure 7).
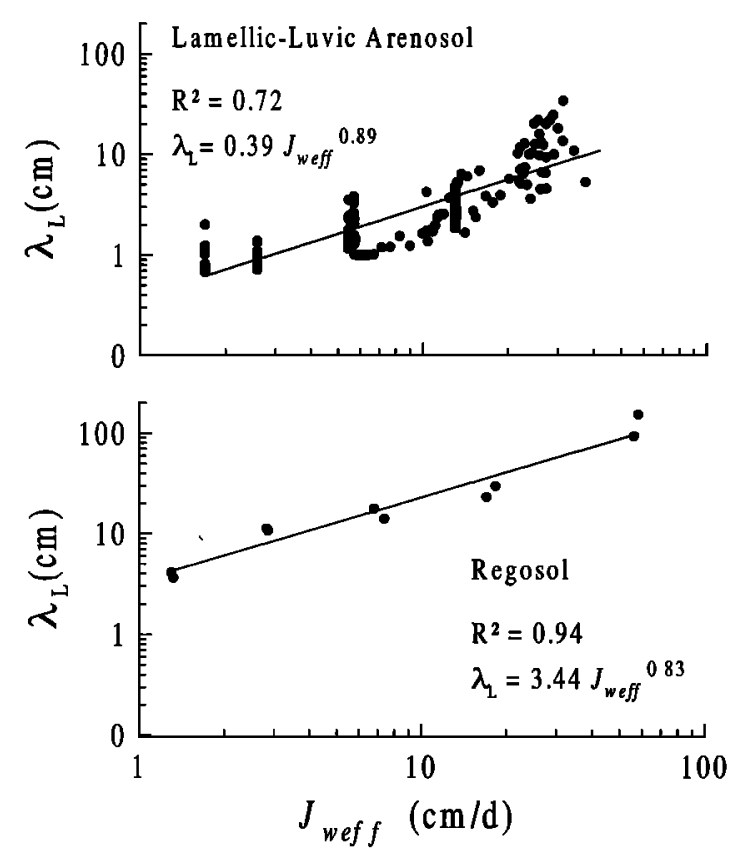

Figure 6. Dispersivity $\lambda_{L}$ versus effective flow rate $J_{\text {weff }}$ in the Lamelli-Luvic Arenosol and the Eutric Regosol. (For the Regosol, $\lambda_{L}$ derived from BTCs at $1 \mathrm{~m}$ depth in the soil profile are shown.) From Vanderborght et al. [2000a].

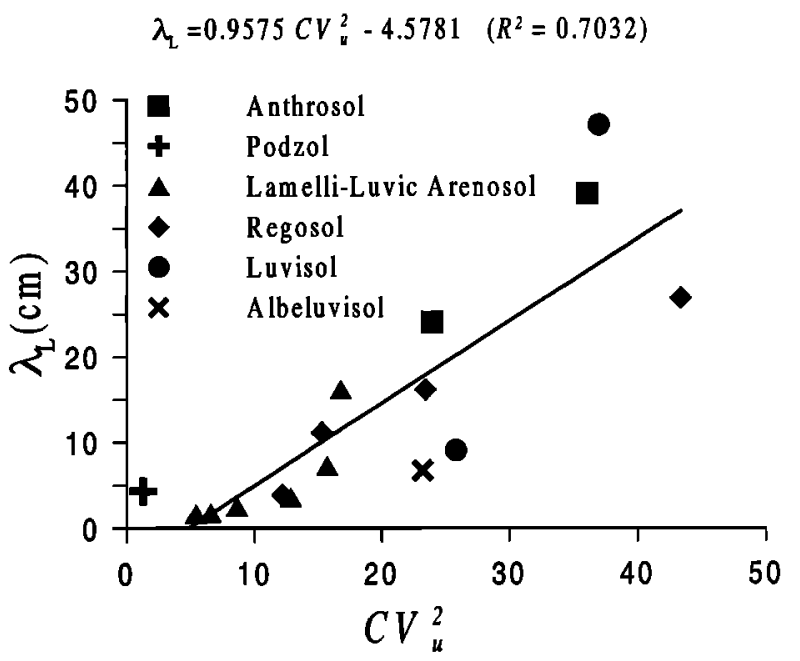

Figure 7. Dispersivity $\lambda_{L}$ observed in different soils and for different flow rates versus the squared coefficient of variation of pore water velocities $C V_{u}^{2}$, which was calculated from the hydraulic conductivity characteristic $K(\theta)$ of the soil and the effective flow rate during the leaching experiment.

\section{Summary and Conclusions}

Table 4 summarizes the lateral mixing regimes observed in the different soils, i.e., convective-dispersive and stochasticconvective, and the dispersivities $\lambda_{L}$ derived from breakthrough curves at $1 \mathrm{~m}$ below the soil surface for various effective flow rates $J_{\text {weff }}$. By comparing results from leaching experiments at various horizontal scales we found that transport experiments in undisturbed soil columns of $30-80 \mathrm{~cm}$ diameter yielded similar estimates of solute dispersion to field experiments along $8 \mathrm{~m}$ long transects. This suggests that in the soils we investigated, the scale of the heterogeneity of solute advection velocities is relatively small in the horizontal direction. However, this conclusion must not be extrapolated to soils with heterogeneous structures such as tongued soil layers, coarser textured layers, and plow pans, which can promote substantial horizontal water and solute redistribution over a distance considerably larger than the size of columns used here.

The vertical scale of the experiment is more important. From the scaling of $\lambda_{L}$ with depth, the mixing regime in the soil profile can be derived, i.e., incomplete lateral solute mixing if $\lambda_{L}$ increases with depth and complete mixing if $\lambda_{L}$ remains constant with depth. If lateral solute mixing is incomplete, $\lambda_{L}$ can increase by more than a factor of 10 over a distance of $1 \mathrm{~m}$. The mixing regime can be linked to morphological features of the soil profile. Leaching of substances is a very important pedogenetic process, and the structure of eluvial and illuvial horizons in the soil profile reflects a leaching process that takes place over a much longer timescale, i.e., hundreds to thousands of years, than the timescale of a leaching experiment. Yet, despite the difference in timescale, our results indicate that the structure of soil horizons can be linked to the mixing regime observed in a leaching experiment. For instance, the horizontally banded lamellic illuvial clay horizon in the Arenosols indicates a homogeneous leaching of clay and iron oxides and points at the convective-dispersive mixing regime which was observed in this soil profile. Also, the cemented top part of the spodic horizon in the Podzol apparently enhanced solute mix- 
Table 4. Summary of Transport Properties of the Different Soils Investigated: Lateral Mixing Regime, Longitudinal Dispersivity $\lambda_{L}$, Observed at $1 \mathrm{~m}$ Below the Soil Surface, and the Relation Between $\lambda_{L}$ and the Effective Flow Rate $J_{w \text { eff }}$

\begin{tabular}{|c|c|c|c|c|c|c|}
\hline Anthrosol & Haplic Podzo] & $\begin{array}{l}\text { Lamellic } \\
\text { Arenosol }\end{array}$ & $\begin{array}{c}\text { Lamelli-Luvic } \\
\text { Arenosol }\end{array}$ & Regosol & Luvisol & Albeluvisol \\
\hline incomplete $\left(\mathrm{SC}^{\mathrm{a}}\right)$ & $\begin{array}{l}\text { below top of spodic } \\
\text { horizon: } \\
\text { complete }\left(\mathrm{CD}^{\mathrm{b}}\right)\end{array}$ & complete (CD) & $\begin{array}{l}\text { Lateral Mixin } \\
\text { complete }(\mathrm{CD})\end{array}$ & $\begin{array}{l}\text { complete at low flow rate } \\
\text { (CD); incomplete at } \\
\text { higher flow rates (SC) }\end{array}$ & incomplete (SC) & incomplete (SC) \\
\hline $\begin{array}{l}24(0.9) \\
39(2.5)\end{array}$ & $4.4(1.0)$ & $\lambda_{L} \mathrm{~cm}$ & 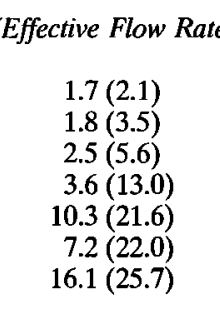 & $\begin{array}{c}\left.J_{\text {weff }} c m d^{-1}\right) \\
3.9(1.0) \\
11.1(2.8) \\
16.1(7.1) \\
26.8(17.6) \\
\\
123.8(56.9)\end{array}$ & $\begin{array}{c}9(0.98) \\
47(2.6)\end{array}$ & $6.7(1.5)$ \\
\hline yes & $n a^{c}$ & na & $\begin{array}{c}\lambda_{L} \text { Increases with } \\
\quad \text { yes, } \\
\lambda_{L}=0.39 J_{\text {weff }}^{0.89}\end{array}$ & $\begin{array}{l}J_{\text {wefr }} ? \\
\quad \lambda_{L}=3.44 J_{\text {weff }}^{0.83}\end{array}$ & yes & na \\
\hline
\end{tabular}

a Stochastic-convective.

${ }^{\mathrm{b}}$ Convective-dispersive.

'Not available.

ing. On the other hand, the vertical tongues of iron- and claydepleted material in the illuvial clay horizon of the Albeluvisol point at the stochastic-convective mixing regime observed in this soil. Besides pedogenetic morphological features, also the occurrence of macropores, especially in fine-textured soils (e.g., Regosol and Luvisol), and of water-repellent layers (e.g., Anthrosol) can be linked to the stochastic-convective mixing regime, which was observed in these soils. Yet, since both indicators of stochastic-convective and convective-dispersive mixing regimes may occur in the same profile, the prediction of the mixing regime on the basis of morphological features might be ambiguous, and we need more experimental data to identify which indicators are more strongly related to the mixing regime. It is also important to note that we cannot extrapolate the observed transport in $1 \mathrm{~m}$ deep soil profiles to greater depths. For the soils in which we observed incomplete lateral solute mixing, the mixing time $t^{*}$ could not be derived, and hence it remains unknown how $\lambda_{L}$ will change with $z$ deeper underground. Furthermore, except for "young" and "undeveloped" soils, the chemical and physical properties of the substrate or parent material, in which the soil developed, are different from the properties of the soil profile.

Our study showed clearly that the dispersivity $\lambda_{L}$ is not a material constant but depends in all soils considered on the flow rate and water content in the soil profile during the leaching experiment. Besides $\lambda_{L}$, also the mixing regime may depend on the flow rate; for example, when macropores are activated at higher flow rates, the mixing regime changes from a convective-dispersive to a stochastic-convective regime. The atmospheric boundary at the soil surface results in large temporal fluctuations of flow rates in the soil profile. Therefore the relation $\lambda_{L}\left(J_{w}\right)$ needs to be defined which implies that leaching experiments should be carried out at various flow rates, preferably at flow rates occurring under natural climatic boundary conditions. Since the effective flow rate $J_{\text {weff }}$, i.e., the flow rate at which most of the water passes a certain depth in the soil profile, determines the solute dispersion, measured precipitation rates rather than rates that are calculated from daily, monthly, or yearly precipitation amounts, should be considered. Whether the $\lambda_{L}\left(J_{w}\right)$ relation, which was derived from leaching experiments under controlled boundary conditions, can be used to describe leaching under climatic boundary conditions is the subject of ongoing research.

The differences in $\lambda_{L}$ between different soils and for different flow rates could be partly explained by the coefficient of variation of the pore water velocities, $\mathrm{CV}_{u}^{2}$, which was derived from the relation between hydraulic conductivity and soil water content, $K(\theta)$, using a multidomain conceptualization of the pore space. However, for macroporous soils, the derivation of $\mathrm{CV}_{u}^{2}$ may still be improved by considering a multimodal conductivity curve. Only the variability of pore water velocities but not the characteristic pore length $l^{*}$, which is related to the mixing time $t^{*}$, can be derived from $K(\theta)$. As a consequence, no perfect relation between $\lambda_{L}$ and $C V_{u}^{2}$ can be expected since $l^{*}$ depends also on the soil type and flow rate.

Both the small horizontal scale of transport heterogeneity and the fact that the $K(\theta)$ relation explains to a large extent the differences in dispersivities between different soil types and flow rates indicate that variations in solute velocities over a small horizontal scale are very important for solute dispersion in soils. Given the sizes of samples on which soil hydraulic properties are determined, it is questionable whether these small-scale velocity variations can be inferred indirectly from the spatial variability of measured soil hydraulic properties. However, using newly developed techniques, distributions of fluorescent tracer concentrations can be obtained with a very high spatial resolution (down to $1 \mathrm{~mm}^{2}$ ) [Aeby et al., 2001]. These concentration patterns could be used to derive information on the horizontal scales and the rate of lateral solute mixing. In addition, comparing the concentration patterns directly to visible soil morphological features, the effect of these features on solute transport could be inferred directly.

Acknowledgments. This research was funded by the following projects: IWONL-project Comité voor de ontwikkeling van een 
bodeminformatiesysteem (COBIS) D 1/4 - 13022/5405A; EC-project EV5V-CT92-0214, Critical parameters governing the mobility and fate of pesticides in the soil/aquifer system; and EC-project EV5V-CT940480 , Risk analysis of the impact of agrochemicals on soil and water quality under farming systems with different land use practices. The first author was a postdoctoral research assistant of the Belgian Fund for Scientific Research, Flanders.

\section{References}

Aeby, P. U. Schultze, D. Braichotte, M. Bundt, F. Moser-Boroumand, $\mathrm{H}$. Wydler, and H. Flühler, Fluorescence imaging of tracer distributions in soil profiles, Environ. Sci. Technol., 35, 753-760, 2001.

Arya, L. M., D. A. Farrell, and G. R. Blake, A field study of soil water depletion patterns in presence of growing soybean roots, $\mathrm{I}$, Determination of hydraulic properties of soil, Soil Sci. Soc. Am. Proc., 39, 424-430, 1975.

Bear, J., Dynamics of Fluids in Porous Media, Elsevier Sci., New York, 764 pp., 1972.

Bouma, J., Influence of soil macroporosity on environmental quality, Adv. Agron., 46, 1-37, 1991.

Bouma, J., C. Belmans, L. W. Dekker, and W. J. M. Jeurissen, Assessing the suitability of soils with macropores for subsurface liquid waste disposal, J. Environ. Qual., 12, 305-311, 1983.

Butters, G. L., and W. A. Jury, Field scale transport of bromide in an unsaturated soil, 2, Dispersion modeling, Water Resour. Res., 25, 1583-1589, 1989.

Chen, C., and R. J. Wagenet, Simulation of water and chemicals in macropore soils, part 1, Representation of the equivalent macropore influence and its effect on soilwater flow, J. Hydrol., 130, 10-126, 1992.

Coats, K. H., and B. D. Smith, Dead end pore volume and dispersion in porous media, Soc. Pet. Eng. J., 4, 73-84, 1964.

Corey, J. C., D. R. Nielsen, and J. W. Biggar, Miscible displacement in saturated and unsaturated sandstone, Soll Sci. Soc. Am. Proc., 27, $258-262,1963$.

Dagan, G., Stochastic modeling of groundwater flow by unconditional and conditional probabilities, 2 , The solute transport, Water Resour. Res., 18, 835-848, 1982.

Dagan, G., Flow and Transport in Porous Formations, Springer-Verlag, New York, 1989.

De Smedt, F., and P. J. Wierenga, Approximate analytical solution for solute flow during infiltration and redistribution, Soil Sci. Soc. Am. J., 42, 407-412, 1978.

De Smedt, F., F. Wauters, and J. Sevilla, Study of tracer movement through unsaturated sand, J. Hydrol., 85, 169-181, 1986.

Durner, W., Hydraulic conductivity estimation for soils with heterogeneous pore structure, Water Resour. Res., 30, 211-223, 1994.

Durner, W., and H. Flühler, Multi-domain models for pore-size dependent transport of solutes in soils, Geoderma, 70, 281-297, 1996.

Dyson, J. S., and R. E. White, The effect of irrigation rate on solute transport in soil during steady state water flow, J. Hydrol., 107, $19-29,1989$.

Einstein, A., Ueber die von der molekularkinetsichen Theorie der Waerme geforderte Bewegung von in ruhenden Fluessigkeiten suspendierten Teilchen, Ann. Phys., 17, 549-560, 1905.

Flühler, H., W. Durner, and M. Flury, Lateral solute mixing processes: A key for understanding field-scale transport of water and solutes, Geoderma, 70, 165-183, 1996.

Flury, M., H. Flühler, W. A. Jury, and J. Leuenberger, Susceptibility of soils to preferential flow of water: A field study, Water Resour. Res., 30, 1945-1954, 1994.

Food and Agriculture Organization, World Reference Base for Soil Resources, World Soil Resour. Rep., 84, 88 pp., Rome, 1998.

Gähwiller, P., Strukturen im Kleinbereich-Röntgentomographisches Bild der räumlichen Struktur eines marmorierten BraunerdePseudogley-Bodens in Rafz, Inst. for Terr. Ecol., Eidg. Tech. Hochsch. Zürich, Switzerland, 1997.

Gardner, W., Some steady state solutions of the unsaturated moisture flow equation with application to evaporation from a water table, Soil Sci., 85, 228-232, 1958.

Gerke, H. H., and M. T. van Genuchten, A dual porosity model for simulating the preferential movement of water and solutes in structured porous media, Water Resour. Res., 29, 305-319, 1993.

Gwo, J. P., P. M. Jardine, G. V. Wilson, and G. T. Yeh, A multiplepore-region concept to modeling mass transfer in subsurface media, J. Hydrol., 164, 217-237, 1995.
Jacques, D., J. Vanderborght, D. Mallants, D.-J. Kim, H. Vereecken, and J. Feyen, Comparison of three stream tube models predicting field-scale solute transport, Hydrol. Earth Syst. Sci., 4, 873-893, 1997.

Jacques, D., D.-J. Kim, J. Diels, J. Vanderborght, H. Vereecken, and J. Feyen, Analysis of steady state chloride transport through two heterogeneous field soils, Water Resour. Res., 34, 2539-2550, 1998.

Jarvis, N. J., P.-E. Jansson, P. E. Dik, and I. Messing, Modeling water and solute transport in macroporous soil, $\mathbf{I}$, Model description and sensitivity analysis, J. Soil Sci., 42, 59-70, 1991.

Jury, W. A., Simulation of solute transport using a transfer function model, Water Resour. Res., 18, 363-368, 1982.

Jury, W. A., and H. Flühler, Transport of chemicals through soil: Mechanisms, models and field application, Adv. Agron., 47, 141-201, 1992.

Jury, W. A., and K. Roth, Transfer Functions and Solute Movement Through Soil: Theory and Application, Birkhauser Boston, Cambridge, Mass., 1990.

Jury, W. A., and G. Sposito, Field calibration and validation of solute transport models for the unsaturated zone, Soil Sci. Soc. Am. J., 49, 1331-1341, 1985.

Kasteel, R., Solute transport in an unsaturated field soil: Describing heterogeneous flow fields using spatial distribution of hydraulic properties, Ph.D. thesis 12477, Eidg. Tech. Hochsch. Zürich, Switzerland, 1997.

Khan, A. U. H., and W. A. Jury, A laboratory study of the dispersion scale effect in column outflow experiments, J. Contam. Hydrol., 5 , 119-131, 1990.

Klotz, D., K.-P. Seiler, H. Moser, and F. Neumaier, Dispersivity and velocity relationship from laboratory and field experiments, J. $\mathrm{Hy}$ drol., 45, 169-184, 1980.

Koch, S., and H. Flühler, Lateral solute mixing in homogeneous and layered sand columns, Geoderma, 63, 109-121, 1994.

Kung, K.-J. S., Preferential flow in a sandy vadose zone, 1, Field observation, Geoderma, 46, 51-58, 1990a.

Kung, K.-J. S., Preferential flow in a sandy vadose zone, 2, Mechanisms and implications, Geoderma, 46, 59-71, 1990b.

Maraqa, M. A., R. B. Wallace, and T. C. Voice, Effects of degree of water saturation on dispersivity and immobile water in sandy soil columns, J. Hydrol., 25, 199-218, 1997.

Neter, J., W. Wasserman, and M. H. Kutner, Applied Linear Statistical Models: Regression, Analysis of Variance, and Experimental Designs, 3rd ed., Irwin, Homewood, Ill., 1990.

Parker, J. C., and M. T. van Genuchten, Flux-averaged and volumeaveraged concentrations in continuum approaches to solute transport, Water Resour. Res., 20, 866-872, 1984.

Passioura, J. B., Hydrodynamic dispersion in aggregated media, 1, Theory, Soil Sci., 111, 339-344, 1971.

Ritsema, C. J., and L. W. Dekker, Distribution flow: A general process in the top layer of water repellent soils, Water Resour. Res., 31, $1187-1200,1995$.

Ritsema, C. J., L. W. Dekker, J. L. Nieber, and T. S. Steenhuis, Modeling and field evidence of finger formation and finger recurrence in a water repellent sandy soil, Water Resour. Res., 34, 555-567, 1998.

Roth, K., and K. Hammel, Transport of conservative chemical through an unsaturated two-dimensional Miller-similar medium with steady state flow, Water Resour. Res., 32, 1653-1663, 1996.

Roth, K., W. A. Jury, H. Flühler, and W. Attinger, Transport of chloride through an unsaturated field soil, Water Resour. Res., 27, 2533-2541, 1991.

Russo, D., On the velocity covariance and transport modeling in heterogeneous anisotropic porous formations, 1 , Saturated flow, Water Resour. Res., 31, 129-137, 1995a.

Russo, D., On the velocity covariance and transport modeling in heterogeneous anisotropic porous formations, 2, Unsaturated flow, $\mathrm{Wa}$ ter Resour. Res., 31, 139-145, $1995 \mathrm{~b}$.

Saffman, P. G., Dispersion due to molecular diffusion and macroscopic mixing in flow through a network of capillaries, J. Fluid Mech., 2, 194-208, 1960.

Seuntjens, P., D. Mallants, C. Cornelis, and P. Geuzens, Grid lysimeter study of non-reactive solute transport through two distinct multilayered Spodosols using TDR and Wick samplers, in Modelling of Transport Processes in Soils at Various Scales in Time and Space: Proceedings of the International Workshop of EurAgEng's Field of Interest on Soil and Water, 24-26 November 1999, Leuven, Belgium, 
edited by J. Feyen and K. Wiyo, pp. 284-294, Wageningen Pers, Wageningen, Netherlands, 1999.

Simmons, C. S., A stochastic-convective transport representation of dispersion in one-dimensional porous media systems, Water Resour. Res., 18, 1193-1214, 1982.

Skopp, J., and W. R. Gardner, Miscible displacement: An interacting flow region model, Soil Sci. Soc. Am. J., 56, 1680-1686, 1992.

Steenhuis, T. S., J.-Y. Parlange, and M. S. Andreini, A numerical model for preferential solute movement in structured soils, Geoderma, 46, 193-208, 1990.

Taylor, G. I., Diffusion by continuous movements, Proc. London Math. Soc., A20, 196-211, 1921.

Taylor, G. I., Dispersion of soluble matter in solvent flowing slowly through a tube, Proc. R. Soc. London, Ser. A, 219, 186-203, 1953.

Van Dam, J. C., J. N. M. Stricker, and P. Droogers, Inverse method to determine soil hydraulic functions from multistep outflow experiments, Soil Sci. Soc. Am. J., 58, 647-652, 1994.

Vanderborght, J., C. Gonzalez, M. Vanclooster, D. Mallants, and J. Feyen, Effects of soil type and water flux on solute transport, Soil Sci. Soc. Am. J., 61, 372-390, 1997a.

Vanderborght, J., D. Jacques, D. Mallants, P.-H. Tseng, and J. Feyen, Comparison between field measurements and numerical simulation of steady-state solute transport in a heterogeneous soil profile, $\mathrm{Hy}$ drol. Earth Syst. Sci., 4, 853-871, 1997b.

Vanderborght, J., A. Timmerman, and J. Feyen, Solute transport for steady-state and transient flow in soils with and without macropores, Soil Sci. Soc. Am. J., 64, 1305-1317, 2000a.

Vanderborght, J., D. Jacques, and J. Feyen, Deriving transport parameters from transient flow leaching experiments by approximate steady-state flow convection-dispersion models, Soil Sci. Soc. Am. J., 64, 1317-1327, 2000b.

van Genuchten, M. T., A closed-form equation for predicting the hydraulic conductivity of soil, Soil Sci. Soc. Am. J., 44, 892-898, 1980.

van Genuchten, M. T., and P. J. Wierenga, Mass transfer studies in sorbing porous media, I, Analytical solutions, Soil Sci. Soc. Am. J., 40, 473-480, 1976.

van Wesenbeeck, I. J., and R. G. Kachanoski, Spatial scale dependence of in situ solute transport, Soil Sci. Soc. Am. J., 55, 3-7, 1991.

van Wesenbeeck, I. J., and R. G. Kachanoski, Effect of variable horizon thickness on solute transport, Soil Sci. Soc. Am. J., 58, 13071316, 1994.

Vervoort, R. W., D. E. Radcliffe, and L. T. Vervoort, Soil structure development and preferential solute flow, Water Resour. Res., 35, 913-928, 1999.

Wang, Z., J. Feyen, and C. J. Ritsema, Susceptibility and predictability of conditions for preferential flow, Water Resour. Res., 34, 21692182, 1998.

Ward, A. L., R. G. Kachanoski, A. P. von Bertoldi, and D. E. Elrick, Field and undisturbed-column measurements for predicting transport in unsaturated layered soil, Soil Sci. Soc. Am. J., 59, 52-59, 1995.

White, R. E., The influence of macropores on the transport of dissolved and suspended matter through soil, Adv. Soil Sci., 3, 95-121, 1985.

Zurmühl, T., and W. Durner, Modeling transient water and solute transport in a biporous soil, Water Resour. Res., 32, 819-829, 1996.

J. Deckers, J. Feyen, L. Hubrechts, and A. Timmerman, Laboratory of Soil and Water, Department of Land Management, Faculty of Agricultural and Applied Biological Sciences, Catholic University of Leuven, Vital Decosterstraat 102, B-3000 Leuven, Belgium. (jan.feyen@agr.kulaiven.ac.be)

J. Diels, International Institute for Tropical Agriculture, PMB 5320, Ibadan, Oyo State, Nigeria. (j.diels@cgiar.org)

C. Gonzalez, Faculty of Engineering, Universidad Nacional de Colombia, Edificio Antionio Nariño, Ala Sur, segundo piso, Ciudad Universitaria, Bogotá, Colombia. (carlosg@ing.unal.edu.co)

D. Jacques and D. Mallants, Research Center for Nuclear Energy, SCK-CEN, Boeretang 200,B-2400 Mol, Belgium. (djacques@ sckcen.be; dmallants@sckcen.be)

D.-J. Kim, Department of Environmental Geosphere Science, Faculty of Science and Engineering, Korea University, Anam Dong 5-1, Sungbuk Ku, Seoul 136-701, Republic of Korea. (djkim@ kuccnx.korea.ac.kr)

P. Suentjens, Flemish Institute for Technological Research, VITO, Boertang 200, B-2400 Mol, Belgium. (piet.seuntjens@vito.be)

M. Vanclooster, Department of Environmental Sciences and Land Management, Faculty of Agricultural Sciences, Catholic University of Louvain, Place Croix du Sud, 2 Box 2, Louvain-La-Neuve B-1348, Belgium. (vanclooster@geru.ucl.ac.be)

J. Vanderborght, Institut für Chemie und Dynamik der Geosphäre, Forschungszentrum Jülich, 52425 Jülich, Germany. (j.vanderborght@fz-juelich.de)

(Received November 20, 2000; revised April 12, 2001; accepted June 11, 2001.) 